\title{
Environmental associations of small ground-dwelling mammals in the Pilbara region, Western Australia
}

\author{
L. A. Gibson and N. L. McKenzie \\ Department of Environment and Conservation, Science Division, PO Box 51, Wanneroo, \\ Western Australia 6946, Australia. Email: Lesley.Gibson@dec.wa.gov.au
}

\begin{abstract}
Small (<50 g) ground-dwelling mammals were sampled as a part of a larger survey of the Pilbara biogeographic region in Western Australia. Environmental attributes influencing the probability of occurrence of individual small mammal species were identified using the multivariate adaptive regression splines (MARS) modelling approach. Interpretation of co-occurrence patterns, based on known habitat associations throughout wider ranges in the Pilbara and/or elsewhere in Australia, was used to facilitate comparisons of sub-sets of the species models. Eighteen species were recorded during this study (mean of 3.4 per survey site [range: 0-7]), but only 14 had sufficient survey records to construct models with reasonable certainty. Complex, non-linear responses were observed for most of the MARS species models, with model performance higher for species with a restricted distribution than the more widely ranging species. Species co-occurrence patterns appeared to be best explained by substrate with three alignments linking species that tend to occur on increasingly sandy, clayey and rocky substrates. Similarly, variables describing the substrate were consistently and strongly represented in the models, indicating that these mammals partition their habitat on substrate type at the local scale in the Pilbara. Climate attributes added little information to the models, although distance to the coast, a surrogate for a range of climatic influences, was important for some species. That all species previously known to occur in this region were recorded in the current study suggests that this fauna is still intact, despite a variety of factors (e.g. pastoralism, weed invasion, inappropriate fire regimes and mining) that have been transforming the region's ecology for more than a century.
\end{abstract}

\section{INTRODUCTION}

Data on the occurrence of small $(<50 \mathrm{~g})$ grounddwelling mammal species were collected as a part of a larger study documenting biodiversity patterns in the Pilbara biogeographic region of Western Australia (Figure 1). Beside opportunistic records, mainly held by the Western Australian Museum, previous ground mammal surveys from the Pilbara have been either localised or species-specific (e.g. Dunlop and Sawle 1983; How et al. 1991; How and Cooper 2002; Biota Environmental Sciences 2005; Bamford Consulting Ecologists 2005), including searches for deposits of recent sub-fossils (A. Baynes, pers. comm.).

At the outset of this study, 41 species of nonvolant mammal had been recorded from the region during the period of European settlement (Table 1). Three biogeographical components were recognisable in this fauna: Torresian, Eyrean (Spencer 1896) and endemic, although at least three of the six 'endemics' extend into adjacent regions such as the Little Sandy Desert (e.g. Start et al. 2000; Western Australian Museum records).
This fauna has collapsed during the last 150 years (McKenzie and Burbidge 2002), and the remainder is dominated by species with mean adult body weights of less than $35 \mathrm{~g}$. Twelve species are now extinct in the region, two persist only on its coastal islands (Pseudomys nanus and Rattus tunneyi) and one (Hydromys chrysogaster) has contracted to the coast (Burbidge et al. 2009). Although known losses of Australian mammals have been confined to species with a mean adult body weight greater than $25 \mathrm{~g}$, the magnitude of this loss far exceeds that reported for any other component of the biota. This points to the particular sensitivity of mammals to the changes that have accompanied European settlement in Australia (e.g. McKenzie et al. 2006) and the consequent need to pay particular attention to the conservation of the remaining species.

Regional conservation planning requires knowledge of biogeographic patterning of biodiversity across the region, as well as an understanding of the factors that define those patterns (Ferrier 2002; Ferrier et al. 2007), including the habitat requirements of each species (Bennett et al. 1991). Patterns in the species composition of small 
ground-dwelling mammals have been investigated in other Australian regions (e.g. Friend and Taylor 1984; Braithwaite et al. 1985; Bradley et al. 1987; McKenzie and Hall 1992; Woinarski et al. 1992; 1994; McKenzie et al. 2000). By relating those patterns to environmental attributes, these studies implicate annual average temperature, substrate type and environmental disturbance as important influences on mammal composition. Temperature has a direct effect on the ecophysiology and consequently habitat selection of many homeotherms (e.g. $\mathrm{McNab}$ 1980). Functional adaptations to sandy, fine-textured or rocky substrates are evident in the foot pads of the dasyurids recorded during these surveys, implying 'stationarity' in habitat use (sensu Hengeveld 1994) over evolutionary timeframes. For example, the sand specialist Sminthopsis youngsoni has bristly foot pads, while the rock specialist $S$. longicaudata has rubbery, striated foot pads (McKenzie et al. 2000). A study by How and Cooper (2002), documenting the occurrence of terrestrial small mammals of Adybos/Woodstock Reserve in the Pilbara, found that assemblages differed across three main habitat types: areas adjacent to rocky breakaways, deep alluvial soils adjacent to a creek and Triodia-dominated habitats on a sandplain.

In interpreting these relationships, better resolution can be achieved by associating environmental attributes with the presence (or abundance) of individual species. The derived statistical models can be used to predict the potential distribution (Ferrier et al. 2002; Araújo and Guisan 2006; Elith and Leathwick 2007; Ferrier et al. 2007) and assist in delineating the specific habitat requirements of each species (e.g. Gibson et al. 2007). Over the past decade, this approach has become increasingly popular and the statistical modelling procedures progressively more sophisticated (e.g. Elith et al. 2006). Emphasis is now being placed on selecting methods that relate the responses of species to environmental predictors more realistically (Austin 2007). For example, generalised linear models (GLM) have been criticised for their limited ability to fit non-linear relationships between species and environmental variables (Austin 2007), and there are now a number of alternative procedures that allow more flexible model-fitting (e.g. Muñoz and Felicísimo 2004; Moisen et al. 2006). Indeed, techniques to model species' distributions are now so numerous (e.g. Guisan and Thuiller 2005; Elith et al. 2006) that the decision on which method to use requires careful consideration (Guisan and Thuiller 2005; Austin 2007).

Generalised additive models (GAM; Hastie and Tibshirani 1990) are one technique commonly used to model complex ecological relationships, using non-parametric smoothing functions to fit non- linear responses. Another, relatively new approach to modelling species distributions that has been shown to perform comparatively well (Moisen and Frescino 2002; Muñoz and Felicísimo 2004; Elith et al. 2006; Leathwick et al. 2006) is the application of multivariate adaptive regression splines (MARS; Friedman 1991). MARS uses piecewise linear fits rather than the smooth functions of a GAM, and is computationally much simpler (Elith et al. 2006). An important consideration with all methods that fit complex functions is the interpretability of the resulting response curves, i.e. are they ecologically meaningful (Austin 2007)?

Here, we use the MARS technique to identify the environmental attributes influencing the occurrence of individual species of small grounddwelling mammals in the Pilbara.

\section{METHODS}

\section{Study area}

The Pilbara biogeographic region encompasses an area of approximately $179,000 \mathrm{~km}^{2}$ (Figure 1). Monthly average maximum temperatures range from $25.3^{\circ} \mathrm{C}$ in July to $37.8^{\circ} \mathrm{C}$ in January, and average minimum temperatures range from $11.8^{\circ} \mathrm{C}$ in July to $25.2^{\circ} \mathrm{C}$ in January (Leighton 2004). The broad near-coastal band has a hot, humid summer with a warm winter while inland areas experience a hot, dry summer and a mild winter. Most rainfall occurs in summer, with occasional cyclonic activity. Average annual rainfall is $290 \mathrm{~mm}$, ranging from a monthly average of $1.7 \mathrm{~mm}$ in September to 66.1 $\mathrm{mm}$ in February. There is substantial year-to-year variation in rainfall, both locally and regionally.

The Pilbara straddles two bioclimatic regions (Beard 1990). The higher rainfall areas inland (the Hamersley Range) and the cooler areas near the coast have a semi-desert tropical climate with 9 to 11 months of dry weather when precipitation is insufficient to sustain growth, but receiving rainfall in summer (Leighton 2004). The rest of the region has a desert climate with summer rain (characterised by up to 12 months without rain) and higher temperatures.

The region corresponds closely to the Pilbara Craton (see McKenzie et al. 2009) and is divided into four geomorphically distinctive subregions. Its northern part, the Chichester subregion, is characterised by undulating Archaean granite and basalt plains that include significant areas of basaltic ranges. Plains support a shrub steppe characterised by Acacia inaequilatera over Triodia wiseana hummock grassland, while Eucalyptus leucophloia tree steppes occur on ranges. It is drained to the north by numerous river systems including the De Grey, Oakover, Nullagine, Shaw, 
Table 1 List of the ground-dwelling mammals recorded in the Pilbara biogeographic region (adapted from McKenzie et al. 2006). EX: extinct in Pilbara; SD-Is: substantial decline in range, now persists only on the region's islands; MABW: mean adult body weight, g; n: endemic; t: Torresian; e: Eyrean; b: Bassian.

\begin{tabular}{|c|c|c|c|c|}
\hline Species & Common Names & Status & MABW & Range \\
\hline \multicolumn{5}{|l|}{ Monotremes } \\
\hline Tachyglossus aculeatus (Shaw, 1792) & Echidna & & 4000 & $e, t, b$ \\
\hline \multicolumn{5}{|l|}{ Dasyurids } \\
\hline Dasycercus cristicauda (Krefft, 1867) & Mulgara & & 115 & e \\
\hline Dasycercus blythi (Waite, 1904) & Ampurta & EX & 148 & e \\
\hline Dasykaluta rosamondae (Ride, 1964) & Little Red Kaluta & & 25 & $\mathrm{n}$ \\
\hline Dasyurus geoffroii Gould, 1841 & Chuditch & EX & 1075 & $e, b$ \\
\hline Dasyurus hallucatus Gould, 1842 & Northern Quoll & & 525 & $\mathrm{t}$ \\
\hline Pseudantechinus woolleyae Kitchener and Caputi, 1988 & Woolley's Antechinus & & 40 & e \\
\hline Pseudantechinus roryi Cooper, Aplin and Adams, 2000 & Tan Antechinus & & 25 & e \\
\hline Phascogale calura Gould, 1844 & Red-tailed Phascogale & EX & 53 & e \\
\hline Planigale 'species 1' (Pilbara WA) & & & 7 & $\mathrm{n}$ \\
\hline Planigale 'species 2' (Pilbara WA) & & & 10 & $\mathrm{n}$ \\
\hline Ningaui timealeyi Archer, 1975 & Pilbara Ningaui & & 8 & $\mathrm{n}$ \\
\hline Sminthopsis longicaudata Spencer, 1909 & Long-tailed Dunnart & & 18 & e \\
\hline Sminthopsis macroura (Gould, 1845) & Stripe-faced Dunnart & & 20 & e \\
\hline Sminthopsis ooldea Troughton, 1965 & Ooldea Dunnart & & 11 & e \\
\hline Sminthopsis youngsoni McKenzie and Archer, 1982 & Lesser Hairy-footed Dunnart & & 10 & e \\
\hline \multicolumn{5}{|l|}{ Bandicoots/Bilbies } \\
\hline Isoodon auratus (Ramsay, 1887) & Golden Bandicoot & EX & 450 & $\mathrm{t}, \mathrm{e}$ \\
\hline Macrotis lagotis (Reid, 1837) & Greater Bilby & & 1500 & e \\
\hline \multicolumn{5}{|l|}{ Possums } \\
\hline Trichosurus vulpecula (Kerr, 1792) & Common Brushtail Possum & & 3000 & $e, b, t$ \\
\hline \multicolumn{5}{|l|}{ Macropods } \\
\hline Bettongia lesueur (Quoy and Gaimard, 1824) & Boodie & EX & 1500 & e \\
\hline Bettongia penicillata Gray, 1837 & Woylie & EX & 1300 & $e, b$ \\
\hline Lagorchestes conspicillatus Gould, 1842 & Spectacled Hare-wallaby & & 3000 & e \\
\hline Lagorchestes hirsutus Gould, 1844 & Rufous Hare-wallaby & EX & 1660 & $\mathrm{e}$ \\
\hline Macropus robustus Gould, 1841 & Euro & & 23500 & $\mathrm{t}, \mathrm{e}$ \\
\hline Macropus rufus (Desmarest, 1822) & Red Kangaroo & & 33500 & e \\
\hline Petrogale lateralis Gould, 1842 & Black-footed Rock-wallaby & EX & 3700 & e \\
\hline Petrogale rothschildi Thomas, 1904 & Rothschild's Rock-wallaby & & 5250 & $\mathrm{n}$ \\
\hline \multicolumn{5}{|l|}{ Rodents } \\
\hline Leggadina lakedownensis Watts, 1976 & Lakeland Downs Mouse & & 18 & $\mathrm{t}$ \\
\hline Leporillus apicalis (Gould, 1853) & Lesser Stick-nest Rat & EX & 125 & e \\
\hline Mesembriomys macrurus (Peters, 1876) & Golden-backed Tree-rat & EX & 205 & $\mathrm{t}$ \\
\hline Notomys alexis Thomas, 1922 & Spinifex Hopping-mouse & & 32 & e \\
\hline Notomys longicaudatus (Gould, 1844) & Long-tailed Hopping-mouse & EX & 80 & e \\
\hline Pseudomys chapmani Kitchener, 1980 & Western Pebble-mound Mouse & & 10 & $\mathrm{n}$ \\
\hline Pseudomys delicatulus (Gould, 1842) & Delicate Mouse & & 12 & $\mathrm{t}, \mathrm{e}$ \\
\hline Pseudomys desertor Troughton, 1932 & Desert Mouse & & 25 & e \\
\hline Pseudomys hermannsburgensis (Waite, 1896) & Sandy Inland Mouse & & 12 & e \\
\hline Pseudomys nanus (Gould, 1858) & Western Chestnut Mouse & SD-Is & 35 & t,e \\
\hline Zyzomys argurus (Thomas, 1889) & Common Rock-rat & & 45 & $e, t$ \\
\hline Zyzomys pedunculatus (Waite, 1896) & Central Rock-rat & EX & 60 & $\mathrm{e}$ \\
\hline Hydromys chrysogaster Geoffroy, 1804 & Water-rat & SD & 700 & $\mathrm{t}, \mathrm{b}$ \\
\hline Rattus tunneyi (Thomas, 1904) & Pale Field-rat & SD-Is & 90 & $t, e^{*}$ \\
\hline
\end{tabular}


Yule and Sherlock. The Fortescue subregion comprises alluvial plains and frontages of the Fortescue River. Salt marsh, mulga low woodland over bunch grass, and short grass communities occur on the alluvial plains, while River Gum woodlands fringe the drainage lines. Scrub steppe occurs on sandstone ranges. Drainage is oriented west-north-west. The Hamersley subregion occupies the southern part of the Pilbara Craton. It is a mountainous area of Proterozoic sedimentary ranges and plateaus dissected by gorges (banded ironstone, basalt, shale and dolerite). Mulga low woodland over bunch grasses occur on finetextured soils, and Eucalyptus leucophloia over Triodia brizoides and T. wiseana hummock grassland characterises skeletal sandy soils of the ranges. It is drained southward into the Ashburton River, westward to the coast via the Robe River and northward into the Fortescue River. The Roebourne subregion comprises the Quaternary alluvial coastal and sub-coastal plains of the region. These support a grass savanna of mixed bunch and hummock grasses, and dwarf shrub steppe of Acacia stellaticeps over soft spinifex of Triodia pungens and T. epactia. Samphire dwarf shrublands, Sporobolus grasslands and low mangrove forests occur on marine alluvial flats and river deltas.

\section{Land-use history}

European activities, including pastoralism, the introduction of exotic plants and feral animals together with mining and associated infrastructure developments, have modified Pilbara vegetation and landscapes, although their effect has been mitigated by the large areas of rugged upland with low pastoral value (Hennig 2004). More than 100 years of over-grazing and frequent wildfires have changed vegetation cover and stripped soils of their organic and mineral-A layers, thereby reducing their water-holding capacities (Van Vreeswyk 2004). Consequently, most of the region's major river systems now carry heavy bed loads of sand, a direct consequence of excessive run-off

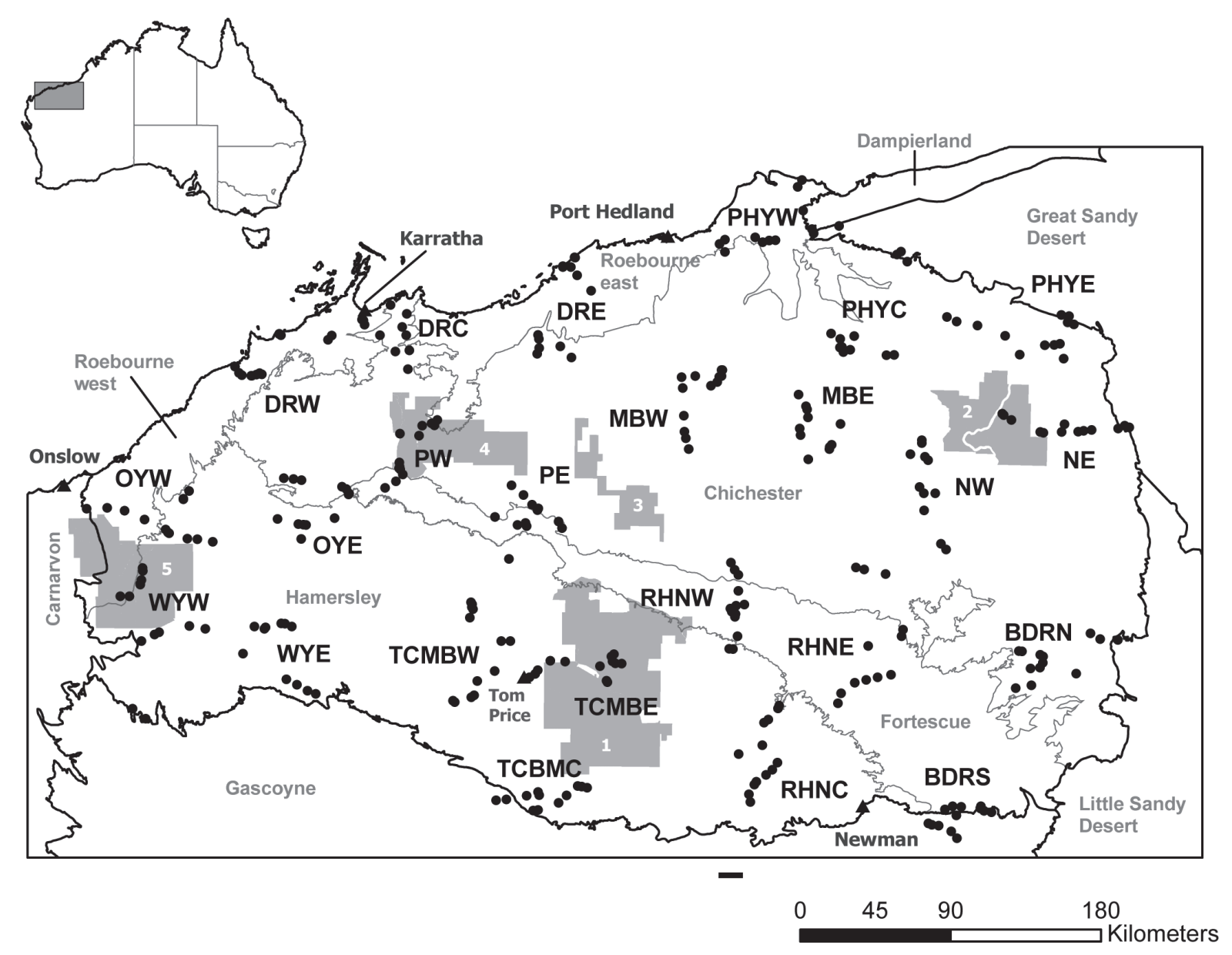

Figure 1 Pilbara biogeographic region. The relative positions of the 24 survey areas are indicated by their labels (e.g. PE, MBW etc.), and the 301 survey sites are marked as circles. Biogeographic region boundaries are shown as bold lines, and boundaries of the four Pilbara sub-regions are grey. Surrounding biogeographic regions and conservation reserves are also shown (1 - Karijini National Park, 2 - Meentheena Conservation Park, 3 - Mungaroona Range Nature Reserve, 4 - Millstream-Chichester National Park and 5 - Cane River Conservation Park). 
Table 2 Environmental variable codes used in the modelling process and their descriptions. Inter-correlated variables removed from the analysis are indicated in bold.

\begin{tabular}{l|l}
\hline Variable code & Description \\
\hline MTEMP & Mean temperature of the coldest period \\
RAIN & Mean annual rainfall \\
SILT & Percent silt \\
NITGN & Total nitrogen (ppm) \\
XCAL & Exchangeable calcium \\
CLAY & Percent clay \\
GCOV & Ground vegetation cover $(\leq 1 \mathrm{~m})$ \\
ELE & Elevation (m above sea level) \\
SLP & Slope (degrees from horizontal) \\
RUG500 & Topographic ruggedness \\
CST & Distance to the coast (km) \\
RIV & Distance to major drainage line $(\mathrm{km})$ \\
FMAX & Maximum coarse fragment size (1-7) \\
OUTCRP & Abundance of rock outcrop (0-5) \\
\hline
\end{tabular}

volumes and velocities in substantial areas of their catchments (Van Vreeswyk 2004). Degradation caused by increased fire frequencies, buffel grass and/or over-grazing is overt throughout the region, with tussock grasslands and chenopod shrublands among the most obviously affected (Van Vreeswyk 2004).

\section{Sampling design}

The Pilbara region was divided into 24 survey areas, positioned so that the geographic extent of the region and likely environmental gradients were sampled (Figure 1). In each survey area there were 11-13 sites, positioned to represent the geomorphic profile (i.e. combination of geology and topographic position), although placement was restricted to habitat examples that were the least disturbed. As far as possible, sites were pseudo-replicated across geomorphic categories among survey areas. To allow for heterogeneity of the stratification units, two sites were positioned in the most extensive geomorphic units of each survey area. In total, 301 sites were sampled for small ground-dwelling mammals (Figure 1).

Each site consisted of 2 lines of 5 pitfall traps, with traps being $10 \mathrm{~m}$ apart and each line of 5 connected by a flywire drift fence $250 \mathrm{~mm}$ high. Pits consisted of PVC pipe (internal diameter of $125 \mathrm{~mm}$ and $600 \mathrm{~mm}$ in length) with a $2 \mathrm{~L}$ plastic jar inserted and a cone-shaped baffle hindering escape. Due to the large area to be sampled, site establishment and sampling occurred in two phases to reduce any loss of sites to wildfire damage, or biases from year-to-year variations in climate. The 24 survey areas (Figure 1) were arrayed in a roughly checker-board pattern (see Mckenzie et al. 2009, figure 6). Sites in the first 12 areas (white squares of the checker-board) were established in mid-2004, sampled in October 2004 then resampled in May 2005. Sites in the other 12 survey areas (black squares of the checker-board) were established in mid-2005, sampled in September/ October 2005 then re-sampled in May 2006. Each sampling session consisted of 7 nights, a total of 140 trap-nights at each site. Accidental captures in the five invertebrate pitfall traps set for one year at each site were also included in the data set.

\section{Selection of variables}

The selection of variables was based on previous studies that examined the influence of environmental attributes on variation in small mammal species composition in Western Australia (e.g. McKenzie and Hall 1992; 1994; McKenzie et al. 2000; Start et al. 2000; How and Cooper 2002), as well as what was known of the habitat requirements of the same species elsewhere in Australia (e.g. Van Dyck and Strahan 2008). A list of the candidate variable set for inclusion in the modelling is shown in Table 2. Climate variables (MTEMP, RAIN) were derived using the BIOCLIM module of ANUCLIM (Houlder et al. 2000). Sitebased soil geochemical variables (SILT, CLAY, NITGN and XCAL) were determined from bulked sub-samples collected from the floristic quadrat $\left(50 \mathrm{~m}^{2}\right)$ at each site. The topographical variables (ELE, SLP and RUG500) were derived from the STRM (Shuttle Radar Topography Mission) 90 m 
resolution Digital Elevation Model (DEM) using Spatial Analyst tools in ArcGIS 9.1 (ESRI Inc., Redlands, California, USA), resampled at $100 \mathrm{~m}$ pixel resolution. Topographic ruggedness (RUG500) was determined by performing a neighbourhood function in ArcGIS (i.e. standard deviation in elevation in a $500 \mathrm{~m}$ radius). Raster layers of distance to the coast (CST) and distance to major drainage lines (RIV) were generated in the GIS from digitised hydrology information supplied by the Department of Environment and Conservation, Perth, Western Australia. The vegetation variable (GCOV) is an index of total ground cover at each site. The cover of each vegetation stratum (i.e. shrubs $<2 \mathrm{~m}$, grasses and sedges) was estimated visually, scored (1: < 2\%, 2: 2-10\%, 3: 10-30\%, 4: 30$70 \%$ and $5:>70 \%)$ and tallied. As an indicator of the 'rockiness' of a site, the variables maximum coarse fragment size (FMAX) and abundance of rock outcrop (OUTCRP) were estimated visually and categorised following that of McDonald et al. (1984).

\section{Model building}

Only species with a prevalence of at least 0.05 were chosen for inclusion in the modelling process (see Table 3). Initially, pairwise Pearson correlations between all the candidate predictor variables were examined and the set reduced to those with Pearson correlations less than 0.8. A high ratio of candidate variables to the number of species observations can lead to over-fitting of the model, i.e. inclusion of spurious variables (Harrell 2001; Burnham and Anderson 2002). As a general rule, no more than $n / 10$ predictors should be included in the final model, where $n$ is the total sample size or, in the case of a binary response, the sample size of the least represented category (Harrell 2001). In this case, expert opinion helped to further reduce the variable set for the species where the limited number of occurrences required it (see Table 4).

The modelling approach used here to fit MARS models to the species presence/absence data set is detailed in Leathwick et al. (2005, 2006), and Elith and Leathwick (2007). Briefly, MARS describes the relationship between a response variable and predictors by fitting piecewise linear basis functions of differing slope, and the inflection point along the range of the predictor where the slope changes is termed a knot. Knots are initially selected in a forward stepwise procedure to produce an overfit model, then a backward pruning routine simplifies the model by removing those that contribute least to the model fit. Additions and deletions are assessed according to changes in the residual squared errors using generalised crossvalidation. All analyses were run in the $\mathrm{R}$ statistical package (R Development Core Team 2004) using the mda library and additional customised code made

Table 3 Small (<50 g) ground-dwelling mammal species recorded during the study, their code name captured. Species included in the analyses are indicated in bold type. $\mathrm{D}=$ dasyurid marsupial, $\mathrm{R}=$ rodent, $\mathrm{N}=$ number of occurrences.

\begin{tabular}{lll}
\hline Species & Code & Prevalence (N) \\
\hline Ningaui timealeyi (D) & NTIM & $0.59(179)$ \\
Planigale sp. 1 (D) & PLA1 & $0.50(149)$ \\
Sminthopsis macroura (D) & SMAC & $0.44(131)$ \\
Pseudomys hermannsburgensis (R) & PHER & $0.42(125)$ \\
Dasykaluta rosamondae (D) & DROS & $0.39(118)$ \\
Pseudomys desertor (R) & PDES & $0.27(80)$ \\
Mus musculus (R) & MMUS & $0.26(77)$ \\
Sminthopsis youngsoni (D) & SYOU & $0.11(33)$ \\
Planigale sp. 2 (D) & PLA2 & $0.11(33)$ \\
Pseudomys chapmani (R) & PCHA & $0.10(29)$ \\
Pseudomys delicatulus (R) & PDEL & $0.06(19)$ \\
Leggadina lakedownensis (R) & LLAK & $0.06(18)$ \\
Pseudantechinus woolleyae (D) & PWOO \\
Zyzomys argurus (R) & ZARG & $0.05(16)$ \\
Notomys alexis (R) & NALE & $0.05(14)$ \\
Sminthopsis longicaudata (D) & SLON & $0.03(9)$ \\
Pseudantechinus roryi (D) & PROR & $0.03(8)$ \\
Sminthopsis ooldea (D) & SOOL & $0.02(5)$ \\
\hline
\end{tabular}


Table 4 Marginal contributions of each predictor variable to the MARS single-species models. Evaluation statistics are also shown - cross validated area under the curve (AUC) and standard error (se) of the ROC analysis and percentage of total deviance explained (\% Dev exp).

\begin{tabular}{l|c|c|c|c|c|c|c|c|c|c|c|c|c|c}
\hline Variable & SYOU & PHER & DROS & PDEL & PDES & NTIM & PCHA & MMUS & SMAC & PLA2 & LLAK & PLA1 & PWOO & ZARG \\
\hline RAIN & 18.7 & 0.0 & 14.2 & - & 15.0 & 23.2 & - & 10.6 & 14.6 & 5.3 & 6.1 & 0.0 & - & - \\
SILT & 57.7 & 17.3 & 33.5 & 24.0 & 0.0 & 0.0 & - & 0.0 & 0.0 & - & - & 9.0 & - & - \\
NITGN & - & 8.1 & 0.0 & 7.3 & 9.6 & 9.7 & 20.8 & 5.5 & 7.5 & - & - & 0.0 & - & - \\
XCAL & - & 0.0 & 0.0 & - & 15.6 & 0.0 & - & 0.0 & 17.0 & 10.6 & 3.3 & 10.1 & - & - \\
CLAY & 28.0 & 10.6 & 21.6 & - & 9.5 & 32.0 & 11.6 & 0.0 & 15.7 & 21.7 & 10.3 & 20.1 & - & - \\
GCOV & - & 0.0 & 0.0 & - & 4.7 & 0.0 & - & 5.7 & 0.0 & - & - & 0.0 & - & - \\
RUG500 & - & 0.0 & 32.4 & - & 0.0 & 23.9 & 0.0 & 4.2 & 10.4 & - & - & 21.7 & 3.5 & 32.3 \\
CST & - & 8.5 & 0.0 & 14.9 & 29.3 & 6.8 & 16.7 & 29.9 & 34.7 & - & - & 21.0 & 5.5 & - \\
RIV & - & 8.7 & 12.9 & 8.9 & 0.0 & 0.0 & - & 8.0 & 0.0 & - & - & 8.1 & - & - \\
FMAX & 14.1 & 0.0 & 0.0 & - & 0.0 & 0.0 & - & 9.5 & 0.0 & - & - & 0.0 & 0.0 & 0.0 \\
OUTCRP & - & 31.3 & 0.0 & - & 0.0 & 0.0 & - & 0.0 & 0.0 & 23.6 & 0.0 & 51.2 & 14.7 & 0.0 \\
AUC & 0.94 & 0.79 & 0.71 & 0.85 & 0.68 & 0.76 & 0.64 & 0.74 & 0.74 & 0.95 & 0.83 & 0.89 & 0.79 & 0.86 \\
AUC se & 0.01 & 0.02 & 0.03 & 0.04 & 0.02 & 0.03 & 0.05 & 0.03 & 0.03 & 0.02 & 0.05 & 0.02 & 0.07 & 0.04 \\
\% Dev & 60.4 & 31.1 & 20.3 & 30.3 & 18.0 & 24.9 & 20.8 & 29.2 & 24.8 & 62.8 & 42.9 & 50.7 & 24.7 & 28.5 \\
exp & & & & & & & & & & & & & \\
\end{tabular}

A dash (-) denotes the a priori removal of a variable from the candidate set. A value of 0.0 indicates variables not retained in the models by the MARS analysis.

available online (see Elith and Leathwick 2007).

The predictive performance of all models was evaluated using the area under the receiver operating characteristic (ROC) curve. A ROC curve is a plot of true positive cases (or sensitivity) against corresponding false positive cases (or 1 - specificity) across a range of threshold values (Fielding and Bell 1997). The area under the curve (AUC) provides a measure of discrimination ability, and varies from 0.5 for a model with discrimination ability no better than random, to 1.0 for a model with perfect discriminatory ability (Pearce and Ferrier 2000). As an independent data set was unavailable, estimates of AUC were obtained using $k$-fold cross validation (CV, see Hastie et al. 2001), dividing the data into 10 subsets for those species occurring on at least 75 sites (25\% prevalence). For species with a prevalence of less than $25 \%$, the data were divided into 5 subsets, the $\mathrm{CV}$ repeated and averaged. AUC values of $0.5-0.7$ are indicative of low accuracy, values of $0.7-0.9$ moderate accuracy, while values of $>0.9$ are considered highly accurate (Manel et al. 2001).

As a framework for comparing MARS response curves, the analysis package PATN (Belbin 1995) was used to cluster species according to their co-occurrences at the 301 sample sites (presenceabsence data). First, the association measure 'Two-step' (Belbin 1980) was used to determine the quantitative relationship between each pair of species, then the dimensionality of the resulting matrix was reduced using Semi-strong Hybrid scaling (Belbin 1991). Finally, a Minimum Spanning Tree was superimposed on the three dimensional scatterplot derived from the ordination. Patterns overt in the scatterplot were assessed extrinsically, in terms of the known habitat associations of component species throughout their wider geographical ranges in Australia (e.g. McKenzie et al. 2000; How and Cooper 2002; Van Dyck and Strahan 2008).

\section{RESULTS}

Eighteen species of small, ground-dwelling mammals were recorded during the study: 10 dasyurid marsupials, 7 native rodents and an introduced rodent (Mus musculus) (Table 3). A revision of the genus Planigale in Western Australia has identified two species in the Pilbara which have yet to be formally described (Norah Cooper, pers. comm.); in Table 3 they are referred to as Planigale sp. 1 and Planigale sp. 2. All but three of the species small enough to be considered 'trappable' (even as sub-adults) by the pitfall method used here were recorded-Zyzomys pedunculatus, Pseudomys nanus and Rattus tunneyi. The first is thought to be extinct in the Pilbara, and the other two now persist in the region on coastal islands. Additionally, a single Dasyurus hallucatus (sub-adult) and Dasycercus 


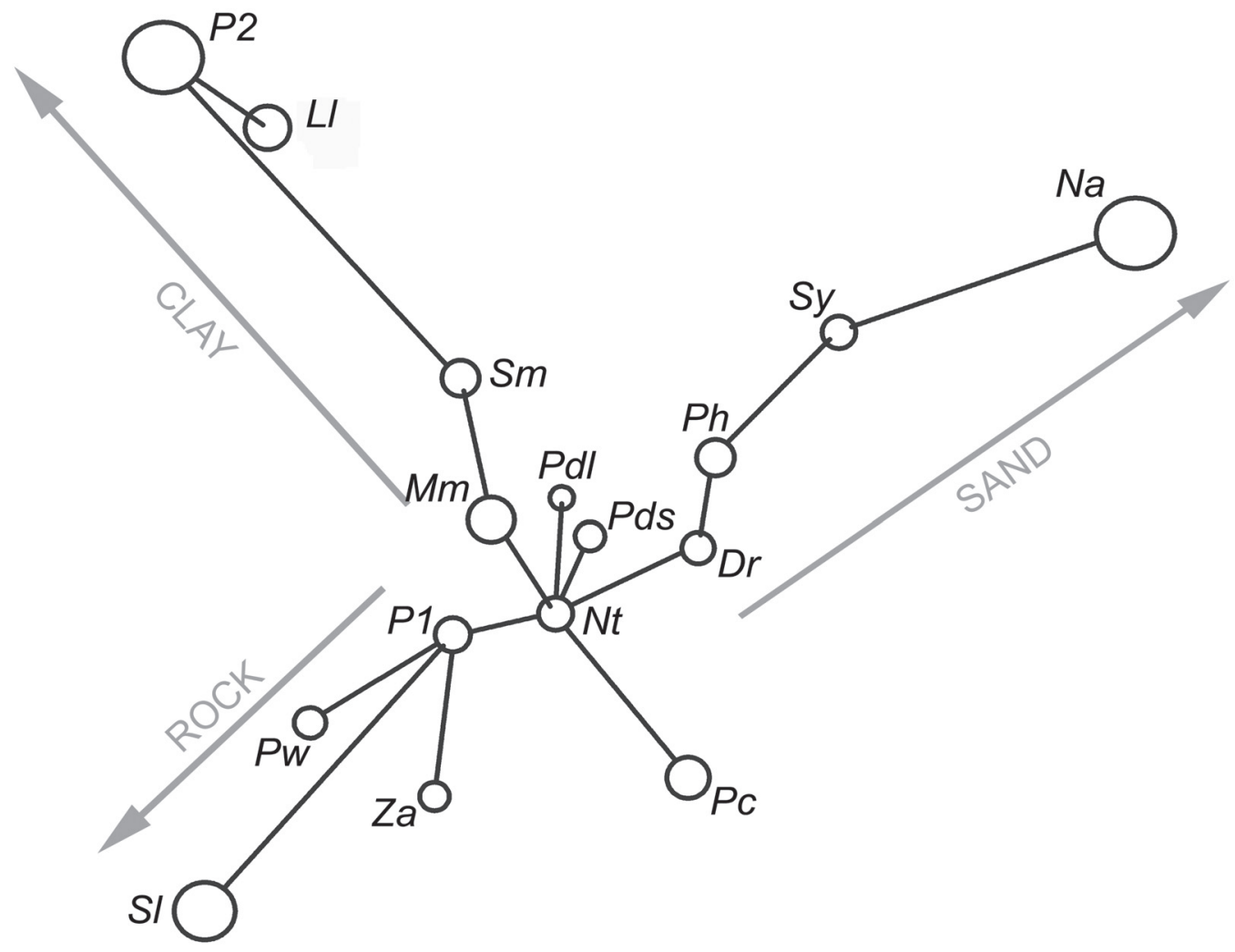

Figure 2 Three-dimensional ordination of the small ground-dwelling mammals according to their co-occurrences at the survey sites (stress $=0.097$ ), with a Minimum Spanning Tree superimposed. The third dimension is indicated by circle diameters. Clay/sand/rock alignments are also shown (extrinsic evidence). Point labels comprise the first letter of the genus name and the first letter of the species name, as listed in Table 3, except P1 and P2 represent Planigale sp. 1 and sp. 2 (respectively), and Pdl: Pseudomys delicatulus; Pds: P. desertor.

cristicaudata were caught incidentally in the invertebrate traps, but these larger (> $50 \mathrm{~g}$ ) species were not targeted in the current survey and were unlikely to be captured by the vertebrate traps (given the design). An average of $3.4 \pm 0.1$ small mammal species were recorded from a total of 140 trap-nights per site (range: 0-7 species/site).

Figure 2 summarises the species co-occurrence patterns. Three distinct alignments extend outwards from the loose central cluster of species with peculiar (P. chapmani) or catholic habitat associations throughout their wider ranges in the Pilbara and/or elsewhere in Australia (P. desertor, $P$. delicatulus and Ningaui timealeyi). Substrate provides a consistent explanation for the patterns overt in this scatterplot, so the alignments are labelled according to substrate-associations of their component species, Australia-wide. Two of the four species forming the loose central cluster, $P$. desertor and $P$. delicatulus, are known to occur on clay, sand and, less frequently, even on rocky surfaces (Braithwaite and Covacevich 1995; Kerle et al. 2008); another, $P$. chapmani, occupies a peculiarly specific category of rocky substrates (gentle pebbly hillslopes; Ford and Johnson 2007), while N. timealeyi (a Pilbara near-endemic) has been reported to occur equally on all three surface-types (Dunlop et al. 2008) which probably explains its central position in the co-occurrence network (Figure 2). The three protruding alignments link species that are faithful to increasingly sandy (Dasykaluta rosamondae, P. hermannsburgensis, Sminthopsis youngsoni then Noto -mys alexis - McKenzie et al. 2000), clayey ( $M$. musculus, S. macroura, Planigale sp. 2 then Leggadina lakedownensis - McKenzie et al. 2000; Moro and Kutt 2008), and rocky substrates (Planigale sp. 1, then $S$. longicaudata, Pseudantechinus woolleyae and Zyzomys argurus diverging outwards - Burbidge et al. 2008; Woolley 2008; Fleming 2008). Because Planigale sp. 1 and Planigale sp. 2 are undescribed species and appear to be restricted to the Pilbara, we base these habitat interpretations on observations made during another (localised) survey in the region (Biota Environmental Sciences 2005).

\section{MARS modelling}


'Mean temperature of the coldest period', 'elevation' and 'distance to the coast' were all highly inter-correlated, as were slope and 'topographic ruggedness'. Distance to the coast was considered the most informative variable of the first three as it is likely to influence a number of climatic factors along with temperature (e.g. humidity), and therefore was retained in preference to the others. Topographic ruggedness (instead of slope) was also selected, as it was considered a better descriptor of the topographic position of the sites, leaving 11 variables in total (Table 2).

For each individual species model, the relative importance of the predictor variables in explaining variation in the probability of occurrence of each species can be determined by an examination of the marginal changes in deviance when dropping each individual variable from the final models (Leathwick et al. 2005). Additionally, inspection of the fitted functions helps to interpret the relationship between the predictors and the dependent variable. Table 4 summarises the contributions of predictor variables to each MARS single-species model. Table 5 describes the plots of the response functions for each species by indicating the knot value (i.e. the inflection point along the range of the predictor where the slope changes) and the sign of the association (positive/ negative or nil) either side of each knot for each predictor. An example of how the values in this table relate to response functions is shown in Figure 3. In addition to the fitted functions, plots of the fitted values in relation to each of the predictors selected for modelling for each species are shown in Appendix 1.

Most of the MARS model response curves showed complex, non-linear responses (Table 5). Using the extrinsic interpretation of co-occurrence patterns above as a basis for comparing subsets of the species' models, the three species from the sand alignment that were modelled (D. rosamondae, P. hermannsburgensis and S. youngsoni) all showed an initial positive association with increasing clay content, but only up to a low percentage ( $\leq$ $10 \%)$, after which there was either no association or a negative association ( $P$. hermannsburgensis). Percent sand in the soil was not included in the candidate variable set as it was assumed to be negatively correlated with percent clay. Subsequent analysis showed this to be the case (Pearson correlation: -0.93). While percent clay was highly ranked in terms of explanatory power (i.e. marginal contribution) for $D$. rosamondae and S. youngsoni, percent silt ranked highest for these two species and was also clearly important for $P$. hermannsburgensis, with occurrences declining with increasing silt content. The abundance of rock outcrop at a site had the highest explanatory power for $P$. hermannsburgensis with a linear negative relationship. Topographic ruggedness was also an important predictor for $D$. rosamondae, with occurrences decreasing with increasing ruggedness, while $S$. youngsoni showed a negative linear relationship with increasing rock fragment size.

For those species along the clay alignment, L. lakedownensis and S. macroura displayed similar responses to percent clay in the soil, with occurrences tending to increase with increasing clay content once a relatively low threshold was reached $(8-11 \%)$. Planigale sp. 2 showed a more complex response, with an initial positive followed by a negative association at $17.5 \%$ and positive again beyond $24 \%$ clay. This dip in the response curve is likely to be an anomaly in the data, given the small number of sites where this species occurred and perhaps under-sampling within this range (i.e. $17-24 \%$ clay). Clay had the highest explanatory
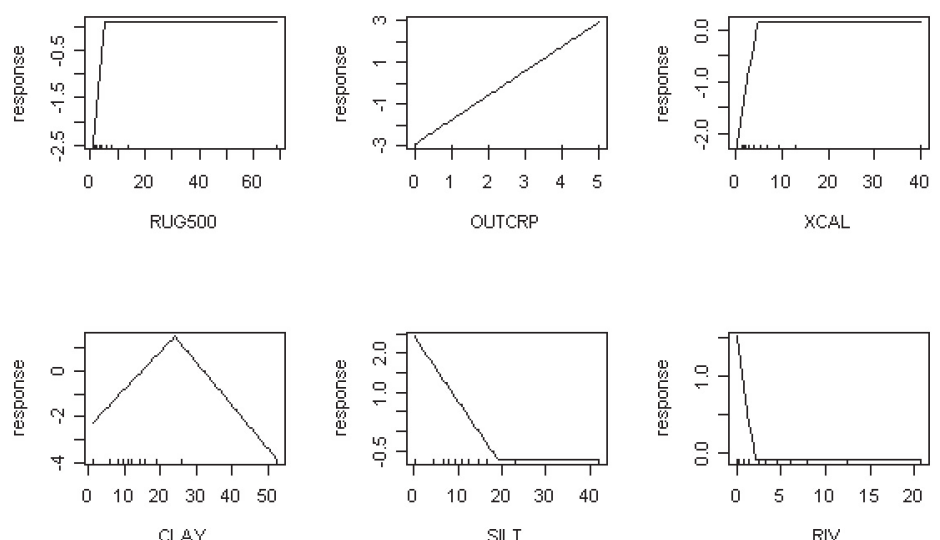

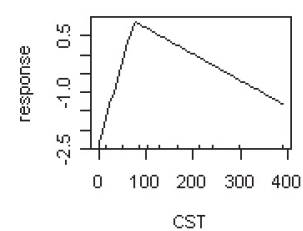

CST

Figure 3 Response functions fitted for Planigale sp. 1 (PLA1) in relation to each environmental variable as listed in Table 5. Equates to the coding in Table 5: RUG500 +[5]; OUTCRP +; XCAL +[5]; CST +[76]-; CLAY +[24]-; SILT $-[19] ;$ and, RIV -[2]. 


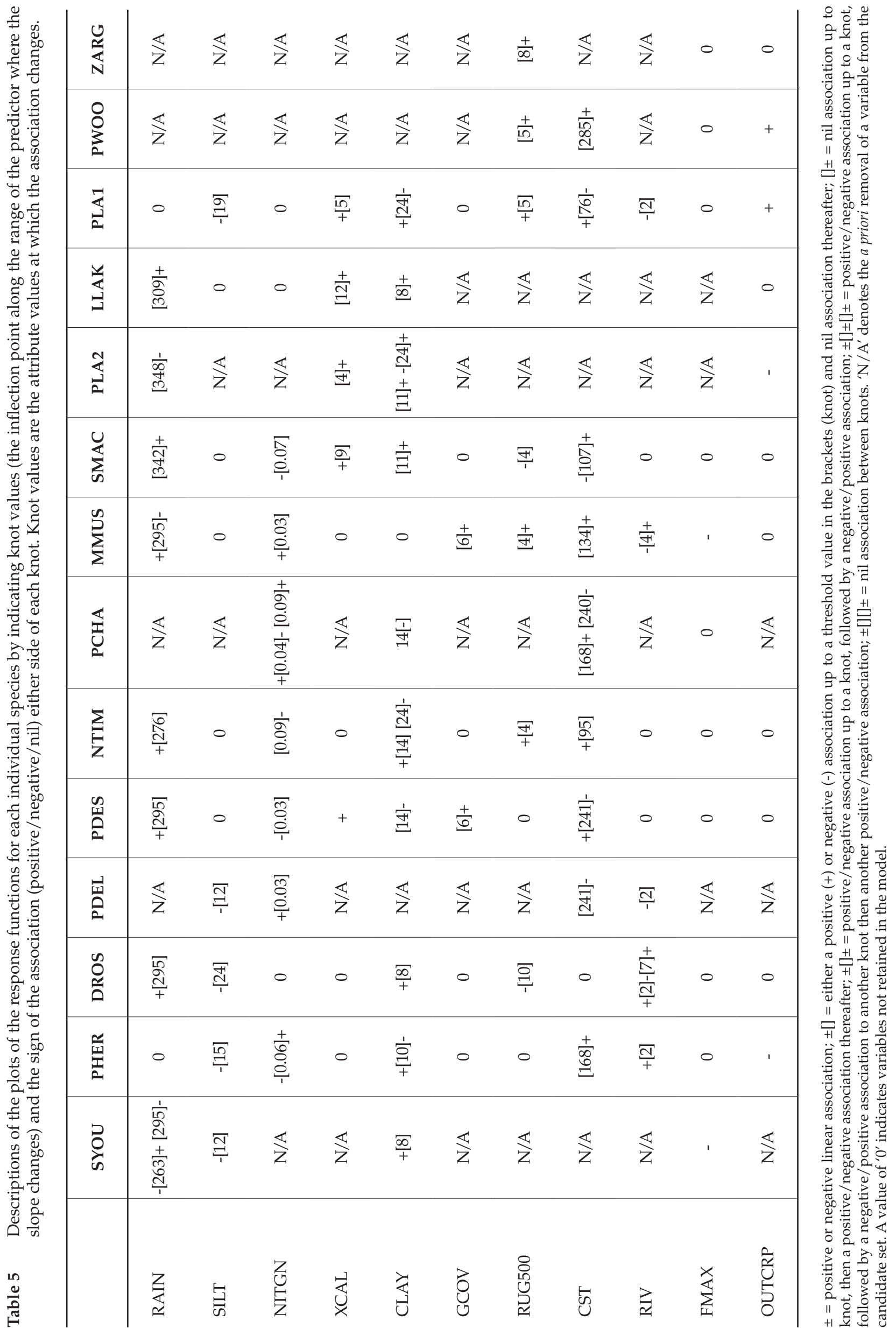


power for L. lakedownensis, and close-to-highest for Planigale sp. 2. The highest ranked variable for the latter was abundance of rock outcrop with occurrences decreasing as more outcrop was exposed. Distance to the coast explained much of the variance for M. musculus and S. macroura, occurrences of both tending to increase with distance to the coast, but only after distances of 134 $\mathrm{km}$ (M. musculus) and $107 \mathrm{~km}$ (S. macroura) had been reached.

For those species extrinsically linked to rocky areas (Figure 2), the abundance of rock outcrop was the main contributor to both Planigale sp. 1 and $P$. woolleyae models, where occurrences increased with greater exposure of rock outcrop. Topographic ruggedness was retained in all three of the rocky species' models and was the sole contributor to the $Z$. argurus model, with positive relationships between occurrence and increasing ruggedness (although thresholds applied - see Table 5).

For the species that occurred in the central cluster of Figure 2, trends across the species were difficult to detect. This is not surprising, however, given the diversity of habitat types that at least three of these species (P. desertor, P. delicatulus and $N$. timealeyi) tend to occupy. Pseudomys delicatulus responded positively to decreasing levels of silt in the soil, but only within a range of 0 to $11.5 \%$. Percent clay was an important predictor of $N$. timealeyi occurrence and distance to the coast for $P$. desertor, but these responses were complex. Percent nitrogen in the soil was the highest ranked variable for $P$. chapmani, with a generally positive response (greater occurrences) to increasing levels.

Other variables not yet mentioned, such as average annual rainfall, exchangeable calcium in the soil, ground cover of vegetation, distance to major drainage lines and maximum fragment abundance, had varying influences in the species models and, for those where these variables were retained, their marginal contributions were generally small.

AUC values obtained from cross-validation ranged from 0.658 for the $P$. chapmani model to 0.950 for Planigale sp. 2, with values tending to be highest for those species with relatively low prevalence such as Planigale sp. 2, S. youngsoni (0.943), Z. argurus (0.860), P. delicatulus (0.853) and L. lakedownensis (0.829) (Table 4). With the exception of Planigale sp. 1 which also had a relatively high AUC of 0.890, the values of species occurring at a high proportion of sites generally fell within the range of $0.7-0.8$. Models with the worst performance were those for P. chapmani and P. desertor, with AUC values of less than 0.7. The percentage of deviance explained by the models largely followed the pattern of the AUC values, and ranged from $18.0 \%$ to $62.8 \%$ (Table 4 ). Models explaining at least half the deviance were those of the two Planigale species and S. youngsoni, with most species' models falling within the range of $20-30 \%$.

\section{DISCUSSION}

That all small $(<50 \mathrm{~g})$ ground-dwelling mammals previously known to occur in the Pilbara biogeographic region were captured in the current study suggests that this fauna is relatively intact. Of the 18 recorded, the most widely caught species were the near-endemic dasyurids, $N$. timealeyi and Planigale sp. 1. Both these species have distributions centred on the Pilbara, but also extend into the margins of the adjacent regions (Western Australian Museum records). Other frequently recorded species include $S$. macroura and $P$. hermannsburgensis, with distributions that extend across Australia's arid zone (Van Dyck and Strahan 2008), and D. rosamondae, another species virtually endemic to the region. Rarely caught, the two false antechinus species ( $P$. woolleyae and $P$. roryi) and the hopping mouse (N. alexis) were likely escapees, given our pit trap dimensions, although Western Australian Museum records reveal that the latter has a patchy distribution in the Pilbara. Records of the long-tailed dunnart (S. longicaudata) were few but this is probably a reflection of their specific habitat preferences rather than rarity as such (A.A. Burbidge, pers. comm.). Little is known of the life history of long-tailed dunnarts, but available evidence suggests that this widely scattered species is restricted to rugged, rocky areas (Burbidge et al. 2008) and, once located, is present in reasonable numbers (M. Cowan, pers. comm.). For instance, eight individuals were trapped over a 5-night period from a 1 ha quadrat on the slopes of the Kennedy Range in May 1995 (McKenzie et al. 2000). In 1981, nine were trapped on a scree slope of the Young Range in the Gibson Desert over a 7-day period (Burbidge et al. 2008). Although there were insufficient Pilbara survey records of S. longicaudata to generate a distributional model with any confidence, sites where they were detected are consistent with the rocky habitat described elsewhere. Another dasyurid, S. ooldea, was detected at only five sites, all in the south-eastern periphery of the Pilbara biogeographic region, which is consistent with their 'southern arid' distribution (Foulkes 2008).

The average species richness per site reported herein $(3.4 \pm 0.1)$ is comparable to values reported from sites of similar size using equivalent trapping regimes in the Carnarvon and southern Murchison regions, elsewhere in arid Western Australia $(2.8 \pm 0.1$ and $3.8 \pm 0.3$, respectively; McKenzie et al. 2000).

\section{Habitat associations}


Disturbance heterogeneity is known to significantly influence small mammal siteoccupancy models (e.g. Woinarski et al. 1992; Catling et al. 2000), so we intentionally reduced its influence on our data by avoiding overtly disturbed examples of habitat types. Also, the analysis presented here presumes a habitat paradigm (see Armstrong 2005), in which species' distributions are determined primarily by habitat characteristics. Under this paradigm we assumed that presences occur in suitable habitat, whereas absences do not. Microhabitat selection and resource availability hypotheses (see Hernández et al. 2005) were treated as second-order effects at regional scales, and not considered. Although this is the first study to define habitat associations influencing the occurrence of small grounddwelling mammals in the Pilbara quantitatively, the results here generally concur with qualitative descriptions of preferred habitat, both within this region (Dunlop and Sawle 1983; How and Cooper 2002; Biota Environmental Sciences 2005; Bamford Consulting Ecologists 2005) and elsewhere in Australia where the species are distributed more widely (McKenzie et al. 2000; Van Dyck and Strahan 2008). Variables describing the substrate were represented consistently and with a high degree of confidence in the MARS models. Such descriptors included percent clay and silt in the soil, and estimates of rockiness and/or ruggedness. Species co-occurrence patterns were also linked extrinsically to substrate, with clay/sand/rock alignments evident. As such, it appears that the small ground-dwelling mammals in the Pilbara partition largely on substrate type at the local scale. McKenzie et al. (2000) reported a similar result for ground-dwelling mammals in the Carnarvon Basin of Western Australia whereby patterns in species composition of mammal assemblages were related to a soil texture gradient. Woinarski et al. (1992) likewise found that a single gradient of substrate and disturbance described the distributions of ground-dwelling mammals in Kakadu National Park in the Northern Territory, with rockiness being the key environmental attribute that most clearly associated with variation in mammal species composition. In the current study, however, as sites were purposely positioned in habitat types that were least disturbed, a disturbance gradient could not be quantified. The species extrinsically associated with the more sandy habitat types ( $D$. rosamondae, P. hermannsburgensis and S. youngsoni) all appear to avoid areas of fine-textured soils (i.e. high silt content), but prefer a small percentage of clay as shown by the initial positive relationship with this variable. The typical appearance of these sandy sites in the Pilbara is illustrated in Plates 1 and 2. Only P. hermannsburgensis demonstrated a negative association as the percentage of clay increased to beyond $10 \%$ but, as the marginal contribution of this variable was not ranked highly, this suggests that this species is not restricted to sandy substrates, which is also supported by other studies both within and outside the Pilbara (McKenzie et al. 2000 ; Breed 2008). That D. rosamondae and $S$. youngsoni showed no association above $8 \%$ clay was somewhat surprising (a negative association was expected) although it seems that silt was a more important attribute in terms of defining occurrence anyway. These three species also tend to avoid rugged, massive rocky habitats, as indicated by their negative associations with topographic ruggedness (D. rosamondae), abundance of rock outcrop (P. hermannsburgensis) or maximum rock fragment size (S. youngsoni).

Core habitat for both L. lakedownensis and Planigale sp. 2 in the Pilbara has been identified as cracking and gilgaied clays (Biota Environmental Sciences 2005). Both species, as well as S. macroura, were commonly caught on these substrates during the current survey, and this is reflected by the positive associations with percent clay and exchangeable calcium in the relevant MARS models. A high level of exchangeable calcium is a characteristic of cracking clays (Barzegar et al. 1994). Here, the cracking clays averaged 19.5 (me\%) exchangeable calcium compared to an overall average of 5.9. Clearly, these species prefer areas of high clay content, but the relative importance of percent clay in the $S$. macroura model was much lower (by approximately one third) than the other two species, indicating a broader habitat preference for this species. Examples of clayey sites where these three species were usually captured in the Pilbara are illustrated in Plates 3 and 4.

While M. musculus is distributed Australia-wide, this species tends to prefer the more fertile habitats in arid regions such as the fine-textured surfaces of alluvial loams and clays, but its distribution expands to occupy other habitats following good seasons when numbers are high (Dunlop and Sawle 1980; Masters 1993; How and Cooper 2002). The MARS model here does not suggest that this species is strongly associated with any particular substrate, with the variation between the marginal contributions of the variables in the MARS model being relatively small (with the exception of distance to the coast).

Observations that the two undescribed Planigale species in the Pilbara separate on habitat type (Biota Environmental Sciences 2005) are confirmed by this study. While Planigale sp. 2 appears to prefer clay substrates and avoids massive rocky habitats, Planigale sp. 1 prefers the rugged substrates dominated by exposed bedrock. These same habitat associations were recognised during a survey in 1979 (see Dunlop and Sawle 1980), although 
the two species were incorrectly assigned as $P$. ingrami (cracking clay habitat) and P. maculata (rocky habitat). While Planigale sp. 1 was associated positively with topographic ruggedness, this relationship was not continuous, i.e. there was no association after a threshold was reached. The other two species associated with rocky habitats, $P$. woolleyae and Z. argurus, did show a continuous positive relationship between occurrence and increasing ruggedness, once this same threshold (or close to it) had been achieved. This is probably a reflection of their more selective preference for the more rugged regions within the Pilbara than Planigale sp. 1, which was more widespread, occurring at almost half the sites. Some of the common rocky habitats in which $Z$. argurus, $P$. woolleyae, Planigale sp. 1 and S. longicaudata were recorded are illustrated in Plates 5 and 6.

In terms of substrate type, the remaining four species showed variable responses. Typical habitat associations in the Pilbara of $P$. delicatulus, $P$. desertor and N. timealeyi are depicted in Plates 7 and 8. Although these species occur across a diversity of habitat types, the Plates illustrate sites where all three were captured most often. Consistent with previous studies, $N$. timealeyi, the most commonly caught species, did not appear to associate with any particular substrate type (How and Cooper 2002; Dunlop et al. 2008). Although percent clay was ranked highly in its MARS model, the response was complex with an initial positive, then negative association with increasing clay content, indicating a preference for some clay, but avoidance of heavy clay substrates such as the cracking clays. Like Planigale sp. 1, N. timealeyi also has a preference for variable topography, but only up to a threshold value. The negative response of $P$. delicatulus to increasing silt content indicates that this species tends to avoid areas high in silt, probably because it prefers more friable soils suitable for burrowing (Ford 2008). The occurrence of $P$. desertor increases with increasing exchangeable calcium content but, unlike the other species associating with exchangeable calcium ('clayey' species), this species responds negatively to increasing clay content. Outside the Pilbara, $P$. desertor has been recorded on a variety of substrate types, from sand plains to limestone and conglomerate scree slopes (Kerle et al. 2008). A common feature of these habitat types is a dense ground cover of vegetation (Kerle et al. 2008), which is consistent with the positive association with ground cover observed in the MARS model here. The last of these four species, P. chapmani, associates positively with soils high in nitrogen but the reason for this is not clear.

According to the bioclimatic modelling, rainfall gradients across the region are weak, with values ranging between 289 and $386 \mathrm{~mm}$ (range: $157 \mathrm{~mm}$ ). Consequently, the regional influence of annual average rainfall did not emerge as an important

Table 6 Small ground mammals extant in Pilbara conservation reserves. X: this study; M: Western Australian Museum specimens collected since 1985.

\begin{tabular}{|c|c|c|c|c|}
\hline Species & $\begin{array}{l}\text { Cane River } \\
\text { Conservation Park }\end{array}$ & $\begin{array}{l}\text { Karijini } \\
\text { National Park }\end{array}$ & $\begin{array}{l}\text { Millstream- } \\
\text { Chichester } \\
\text { National Park }\end{array}$ & $\begin{array}{l}\text { Meentheena } \\
\text { Conservation Park }\end{array}$ \\
\hline Dasykaluta rosamondae & $x$ & $X$ & $X$ & $X$ \\
\hline Leggadina lakedownensis & & & $X$ & M \\
\hline Mus musculus & & $x$ & & $x$ \\
\hline Ningaui timealeyi & $x$ & $x$ & $X$ & $X$ \\
\hline Notomys alexis & $x$ & & & M \\
\hline Planigale sp. 1 & $x$ & $x$ & $x$ & $x$ \\
\hline Planigale sp. 2 & M & & $x$ & \\
\hline Pseudomys chapmani & M & $x$ & $x$ & $x$ \\
\hline Pseudomys delicatulus & M & & M & \\
\hline Pseudomys desertor & & $x$ & $x$ & $x$ \\
\hline Pseudomys hermannsburgensis & $x$ & $x$ & & $x$ \\
\hline Pseudantechinus roryi & & & & M \\
\hline Pseudantechinus woolleyae & & & M & M \\
\hline Sminthopsis macroura & $x$ & $x$ & $x$ & M \\
\hline Sminthopsis youngsoni & $x$ & & & M \\
\hline Zyzomys argurus & M & M & M & M \\
\hline
\end{tabular}


variable in the models (except for $N$. timealeyi). However, 'distance to the coast', a distal variable representing a range of climatic influences and highly correlated with 'mean temperature of the coldest period', had high explanatory power for species such as $S$. macroura, $M$. musculus, $P$. desertor and Planigale sp. 1. The climate of the Pilbara's coastal band differs from the inland areas in terms of higher humidity and a warmer winter. The two species that show a predominantly positive response with increasing distance to the coast, namely S. macroura and P. desertor, have distributions centred largely on Australia's arid interior. The initial positive, then negative response of Planigale sp. 1 to increasing distance to coast reflects the distribution of this endemic species; it is most common in the central Pilbara. It is not clear why this variable was important for M. musculus as this introduced species is generally thought to be widely spread across the landscape (Singleton 2008).

\section{Model performance}

Models of those species with a restricted distribution in the Pilbara tended to perform better than those of the more widely ranging species. For example, the models of Planigale sp. 2 and $S$. youngsoni, both with a prevalence of 0.11, had AUC values greater than 0.9. At greater than $60 \%$, the deviance explained by both these models was also highest. As discussed above, Planigale sp. 2 tends to occur in the heavy clay habitats such as cracking clays and S. youngsoni appears to be restricted to sandy substrates. The more prevalent species (> 0.4 ) fell within the AUC range of 0.7-0.8, with the exception of Planigale sp. 1 which had a higher AUC of 0.89. Leathwick et al. (2005) reported a similar result for MARS models of fish species, and suggested that the superior performance of the restricted species was a result of the ability of the models to identify correctly the extensive areas where species were absent. Intuitively, the ability of a model to discriminate between 'good' and 'bad' habitat for a 'specialist' species is likely to be better than for a 'generalist' species that occurs in a variety of habitat types.

Poor performing models were observed for two of the native rodents ( $P$. desertor and $P$. chapmani) with AUC values less than 0.7. Elsewhere in Australia, $P$. desertor occupies a diverse range of habitat types (Kerle et al. 2008), suggesting that this species is a habitat generalist and probably explains the poor model performance observed here. On the other hand, P. chapmani has specific habitat requirements, mainly relating to their shelter of pebble mounds (Start et al. 2000; Ford and Johnson 2007). Broadly, the occurrence of this species is associated with hilly areas dominated by erosional processes to produce the pebbly substrates they prefer, and avoidance of sand and clay plains (Ford and Johnson 2007). More specifically, as indicated by the presence of pebble mounds, this species tends to occur on the gentle slopes of hills (slope angles of between $2^{\circ}$ and $6^{\circ}$ ), and substrates with pebbles of a specific range size (Start et al. 2000). The poor performance of the P. chapmani model in the current study indicates that variables approximating the specific habitat requirements of this species were missing.

\section{Conservation implications}

An intact small ground-dwelling mammal fauna persists across the Pilbara's landscapes despite the variety of factors that have been transforming the region's ecology for more than 100 years, including pastoralism, mining, inappropriate fire regimes, weed invasion and feral mammal colonisation. This component of the region's fauna shows coherent relationships with environmental attributes, especially soil texture and geomorphology. These habitat associations provide the best available basis for conservation planning. Encompassing substantial areas in three of the Pilbara's four subregions, the existing conservation reserve system includes examples of a wide variety of the sandy, clayey and rocky substrates and geomorphic units that characterise the Pilbara (McKenzie et al. 2003) and, consequently, populations of virtually its entire small ground-dwelling mammal species. Sixteen of the 18 small ground mammals recorded during this study are known to be extant in Pilbara conservation reserves (see Table 6). The only exceptions are Sminthopsis longicaudata and S. ooldea. However, apparently suitable habitat for S. longicaudata is present in one of the reserves, Karijini National Park (Thorne and Tyler 1997), and it is known from several locations near the town of Tom Price on the Park's western periphery (this survey). Also, the geographical range of $S$. ooldea is centred on regions east and south of the Pilbara, only overlapping the Pilbara in the southeastern corner (Foulkes 2008). If the reserves are managed to maintain the integrity of the plant and invertebrate communities associated with the above surfaces, they should be adequate to allow the relevant species to persist in the region. If, however, populations of S. longicaudata are not found in Karijini National Park, one option may be to extend the Park westwards to encompass known populations near Tom Price.

\section{ACKNOWLEDGEMENTS}

We thank Jim Rolfe, Bob Bromilow and Tom Smith and their teams of cadets for establishing the trap sites. Stephen van Leeuwen and Allan Burbidge assisted with site selection. Allan 
Burbidge, Paul Doughty, Brad Durrant, Nadine Guthrie, Neil Hamilton, Kathy Himbeck, Michael Hughes, Brent Johnson, Ron Johnstone, Peter Kendrick, Keith Morris, David Pearson, Jim Rolfe, Claire Stevenson, Neil Thomas and all the volunteers who assisted with the field sampling program are acknowledged. Norah Cooper facilitated access to Western Australian Museum collections. Thanks to Stephen van Leeuwen and two anonymous reviewers for comments on the manuscript. Stephen van Leeuwen also provided plant species names for the Plates. Funding was provided by the Western Australian Department of Environment and Conservation, the Western Australian Museum and the Natural Heritage Trust.

\section{REFERENCES}

Araújo, M.B. and Guisan, A. (2006). Five (or so) challenges for species distribution modelling. Journal of Biogeography 33: 1677-1688.

Armstrong, D.P. (2005). Integrating the metapopulation and habitat paradigms for understanding broad-scale declines of species. Conservation Biology 19: 1402-1410.

Austin, M. (2007). Species distribution models and ecological theory: a critical assessment and some possible new approaches. Ecological Modelling 200: 1-19.

Bamford Consulting Ecologists (2005). Fauna survey of proposed iron ore mine, Cloud Break. Unpublished report prepared for Fortescue Metals Group.

Barry, S. and Elith, J. (2006). Error and uncertainty in habitat models. Journal of Applied Ecology 43: 413-423.

Barzegar, A.R., Murray, R.S., Churchman, G.J. and Rengasamy, P. (1994). The strength of remoulded soils as affected by exchangeable cations and dispersible clay. Australian Journal of Soil Research 32: 185-199.

Beard, J.S. (1990). Plant life of Western Australia. Kangaroo Press: Kenthurst, Australia.

Belbin, L. (1980). TWOSTEP: a program incorporating asymmetric comparisons that uses two steps to produce a dissimilarity matrix. CSIRO Division of Land Use Research Technical Memorandum 80/9. CSIRO: Canberra, Australia.

Belbin, L. (1991). Semi-strong Hybrid Scaling: a new ordination algorithm. Journal of Vegetation Science 2: 491-496.

Belbin, L. (1995). PATN technical reference. CSIRO Division of Wildlife and Ecology: Canberra, Australia.

Bennett, A.F., Lumsden, L.F., Alexander, J.S.A., Duncan, P.E., Johnson, P.G., Robertson, P. and Silveria, C.E. (1991). Habitat use by arboreal mammals along an environmental gradient in north-eastern Victoria. Wildlife Research 18: 125-146.

Biota Environmental Sciences (2005). Fauna habitats and fauna assemblage of Mesa $A$ and $G$, near Pannawonica. Unpublished report prepared for Robe River Iron Associates.

Bradley, A.J., Kemper, C.M., Kitchener, D.J., Humphreys, W.F. and How, R.A. (1987). Small mammals of the
Mitchell Plateau region, Kimberley, Western Australia. Australian Wildlife Research 14: 397-413.

Braithwaite, R.W. and Covacevich, J. (1995). Delicate Mouse Pseudomys delicatulus (Gould 1842) (pp 592593). In: Strahan, R. (ed.), The mammals of Australia. $2^{\text {nd }}$ edn. Reed Books: Sydney, Australia.

Braithwaite, R.W., Winter, J.W., Taylor, J.A. and Parker, B.S. (1985). Patterns of diversity and structure of mammalian assemblages in the Australian tropics. Australian Mammalogy 8: 171-186.

Breed, W.G. (2008). Sandy Inland Mouse Pseudomys hermannsburgensis (Waite 1896) (pp 636-637). In: Van Dyke, S. and Strahan, R. (eds), The mammals of Australia, $3^{\text {rd }}$ edn. Reed New Holland: Sydney, Australia.

Burbidge, A.A., McKenzie, N.L. and Fuller, P.J. (2008). Long-tailed Dunnart Sminthopsis longicaudata Spencer 1909 (pp -). In: Van Dyke, S. and Strahan, R. (eds), The mammals of Australia, $3^{\text {rd }}$ edn Reed New Holland: Sydney, Australia.

Burnham, K.P. and Anderson, D.R. (2002). Model selection and multimodel inference. a practical information-theoretic approach, $2^{\text {nd }}$ edn. Springer: New York, U.S.A.

Catling, P.C., Burt, R.J. and Forrester, R.I. (2000). Models of the distribution and abundance of ground-dwelling mammals in the eucalypt forests of north-eastern New South Wales in relation to habitat variables. Wildlife Research 27: 639-654.

Dunlop, J.N., Cooper, N.K. and Teale, R.J. (2008). Pilbara Ningaui Ningaui timealeyi Archer 1975 (pp 119-120). In Van Dyke, S. and Strahan, R. (eds), The mammals of Australia, $3^{\text {rd }}$ edn. Reed New Holland: Sydney, Australia.

Dunlop, J.N. and Sawle, M. (1983). The small mammals of the Eastern Pilbara and the Hamersley Range National Park (pp 26-20). In: Muir, B.G. (ed.), A fauna survey of the Hamersley Range National Park Western Australia 1980. National Parks Authority of Western Australia: Perth, Australia.

Elith, J., Graham, C.H., Anderson, R.P., Didík, M., Ferrier, S., Guisan, A., Hijmans, R.J., Huettmann, F., Leathwick, J.R., Lehmann, A., Li, J., Lohmann, L.G., Loiselle, B.A., Manion, G., Mortiz, C., Nakamura, M., Nakazawa, Y., Overton, J. McC., Peterson, A.T., Phillips, S.J., Richardson, K.S., Scachetti-Pereira, R., Schapire, R.E., Soberó, J., Williams, S., Wisz, M.S. and Zimmermann, N.E. (2006). Novel methods improve prediction of species' distributions from occurrence data. Ecography 29: 129-151.

Elith, J. and Leathwick, J. (2007). Predicting species distributions from museum and herbarium records using multiresponse models fitted with multivariate adaptive regression splines. Diversity and Distributions 13: 265-275.

Ferrier, S. (2002). Mapping spatial pattern in biodiversity for regional conservation planning: where to from here? Systematic Biology 51: 331-363.

Ferrier, S., Manion, G., Elith, J. and Richardson, K. (2007). Using generalised dissimilarity modelling to analyse and predict patterns of beta diversity in regional biodiversity assessment. Diversity and Distributions 13: 252-264. 
Ferrier, S., Watson, G., Pearce, J. and Drielsma, M. (2002). Extended statistical approaches to modelling spatial pattern in biodiversity in northeast New South Wales. I. Species-level modelling. Biodiversity and Conservation 11: 2275-2307.

Fielding, A.H. and Bell, J.F. (1997). A review of methods for the assessment of prediction errors in conservation presence/absence models. Environmental Conservation 24: 38-49.

Fleming, M.R. (2008). Common Rock-rat Zyzomys argurus (Thomas 1889) (pp 652-654). In: Van Dyke, S. and Strahan, R. (eds), The mammals of Australia, $3^{\text {rd }}$ edn. Reed New Holland: Sydney, Australia.

Ford, F. (2008). Delicate Mouse Pseudomys delicatulus (Gould 1842) (pp 623-624). In: Van Dyke, S. and Strahan, R. (eds), The mammals of Australia, $3^{\text {rd }}$ edn. Reed New Holland: Sydney, Australia.

Ford, F. and Johnson, C. (2007). Eroding abodes and vanished bridges: historical biogeography of the substrate specialist pebble-mound mice (Pseudomys). Journal of Biogeography 34: 514-523.

Foulkes, J.N. (2008). Ooldea Dunnart Sminthopsis ooldea Troughton 1965 (pp 154-156). In: Van Dyke, S. and Strahan, R. (eds), The mammals of Australia, $3^{\text {rd }}$ edn. Reed New Holland: Sydney, Australia.

Friedman, J.H. (1991). Multivariate adaptive regression splines. Annals of Statistics 19: 1-141.

Friend, G.R. and Taylor, J.A. (1984). Ground surface features attributable to feral buffalo, Bubalus bubalus. II. Their relationship to the abundance of small animal species. Australian Wildlife Research 11: 311-323.

Gibson, L., Barrett, B. and Burbidge, A.H. (2007). Dealing with uncertain absences in habitat modelling: a case study of a rare ground-dwelling parrot. Diversity and Distributions 13: 704-713.

Guisan, A. and Thuiller, W. (2005). Predicting species distribution: offering more than simple habitat models. Ecology Letters 8: 993-1009.

Harrell, F.E. (2001). Regression modelling strategies with applications to linear models, logistic regression and survival analysis. Springer-Verlag: New York, U.S.A.

Hastie, T.J. and Tibshirani, R.J. (1990). Generalized additive models. Chapman and Hall: New York, U.S.A.

Hastie, T., Tibshirani, R.J. and Friedman, J.H. (2001). The elements of statistical learning: data mining, inference and prediction. Springer-Verlag: New York, U.S.A.

Hengeveld, R. (1994). Biogeographical ecology. Journal of Biogeography 21: 341-351.

Hennig, P. (2004). A brief land-use history (pp 13-18). In: Van Vreeswyk, A.M.E., Payne, A.L., Leighton, L.A. and Hennig, P. (eds), An inventory and condition survey of the Pilbara region, Western Australia. Technical Bulletin No. 92, Department of Agriculture: Perth, Australia.

Hernández, L., Romero, A.G., Laundré, J.W., Lightfoot, D., Aragón, E. and López Portillo, J. (2005). Changes in rodent community structure in the Chihuahuan Desert, México: comparisons between two habitats. Journal of Arid Environments 60: 239-257.

Houlder, D.J., Hutchinson, M.F., Nix, H.A. and McMahon, J.P. (2000). ANUCLIM user guide, version 5.1. Centre for Resource and Environmental Studies, Australian
National University: Canberra, Australia.

How, R.A. and Cooper, N.K. (2002). Terrestrial small mammals of the Abydos Plain in the north-eastern Pilbara, Western Australia. Journal of the Royal Society of Western Australia 85: 71-82.

How, R.A., Dell, J. and Cooper, N.K. (1991). Vertebrate fauna of the Abydos-Woodstock Reserve, northeast Pilbara. Records of the Western Australian Museum, Supplement 37: 78-125.

Kearle, J.A., Kutt, A.S. and Read, J.L. (2008). Desert Mouse Pseudomys desertor Troughton 1932 (pp 625-626). In: Van Dyke, S. and Strahan, R. (eds), The mammals of Australia, $3^{\text {rd }}$ edn. Reed New Holland: Sydney, Australia.

Leathwick, J.R., Elith, J. and Hastie, T. (2006). Comparative performance of generalized additive models and multivariate adaptive regression splines for statistical modelling of species distributions. Ecological Modelling 199: 188-196.

Leathwick, J.R., Rowe, D., Richardson, J., Elith, J. and Hastie, T. (2005). Using multivariate adaptive regression splines to predict the distributions of $\mathrm{New}$ Zealand's freshwater diadromous fish. Freshwater Biology 50: 2034-2052.

Leighton, K.A. (2004). Climate (pp 19-38). In: Van Vreeswyk, A.M.E., Payne, A.L., Leighton, L.A. and Hennig, P. (eds), An inventory and condition survey of the Pilbara Region, Western Australia. Technical Bulletin No. 92, Department of Agriculture: Perth, Australia.

Manel, S., Williams, H.C. and Ormerod, S.J. (2001). Evaluating presence-absence models in ecology: the need to account for prevalence. Journal of Applied Ecology 38: 921-931.

Masters, P. (1993). The effects of fire-driven succession and rainfall on small mammals in spinifex grassland at Uluru National Park, Northern Territory. Wildlife Research 20: 803-813.

May, J.E. and McKenzie, N.L. (eds) (2002). A biodiversity audit of Western Australia's biogeographical subregions in 2002. Department of Conservation and Land Management: Perth, Australia.

McDonald, R.C., Isabelle, R.L., Speight, J.G., Walker, J. and Hopkins, M.S. (1984). Australian soil and land survey field handbook. $2^{\text {nd }}$ edn. Inkata Press: Melbourne, Australia.

McKenzie, N.L. and Burbidge, A.A. (2002). Mammals (pp 84-96). In: Sattler, P. and Creighton, C. (eds), Australian terrestrial biodiversity assessment 2002. National Land and Water Resources Audit: Canberra, Australia.

McKenzie, N.L., Burbidge, A.A., Baynes, A., Brereton, R., Dickman, C.R., Gibson, L.A., Gordon, G., Menkhorst, R.W., Robinson, A.C., Williams, M.R. and Woinarski, J.C.Z. (2006). Analysis of factors implicated in the recent decline of Australia's mammalian fauna. Journal of Biogeography 34: 597-611.

McKenzie, N.L. and Hall, N.J. (1992). A biological survey of the eastern Goldfields of Western Australia. Part 8. The Kurnalpi - Kalgoorlie Study Area. Records of the Western Australian Museum, Supplement 41: 1-125.

McKenzie, N.L. and Hall, N.J. (1994). A biological survey of the eastern Goldfields of Western Australia. Part 10. 
The Sandstone - Sir Samuel and Laverton - Leonora Study Areas. Records of the Western Australian Museum, Supplement 47: 1-166.

McKenzie, N.L., Hall, N. and Muir, W.P. (2000). Nonvolant mammals of the southern Carnarvon Basin, Western Australia. Records of the Western Australian Museum, Supplement 61: 479-510.

McKenzie, N.L., May, J.E. and McKenna, S. (2003). Bioregional summary of the 2002 biodiversity audit for Western Australia. Department of Conservation and Land Management: Perth, Australia.

McNab, B.K. (1980) Food-habits, energetics, and the population biology of mammals. American Naturalist 116: 106-124.

Moisen, G.G., Freeman, E., Blackard, J., Frescino, T., Zimmermann, N.E. and Edwards, T.C. Jr (2006). Predicting tree species presence in Utah: a comparison of stochastic gradient boosting, generalized additive models, and tree-based methods. Ecological Modelling 199: 176-187.

Moisen, G.G. and Frescino, T.S. (2002). Comparing five modelling techniques for predicting forest characteristics. Ecological Modelling 157: 209-225.

Moro, D. and Kutt, A.S. (2008). Northern Short-tailed Mouse Leggadina lakedownensis Watts 1976 (pp 583-584). In: Van Dyke, S. and Strahan, R. (eds), The mammals of Australia, $3^{\text {rd }}$ edn. Reed New Holland: Sydney, Australia.

Muñoz, J. and Felicísimo, A.M. (2004). Comparison of statistical methods commonly used in predictive modelling. Journal of Vegetation Science 15: 285-292.

Pearce, J. and Ferrier, S. (2000). Evaluating the predictive performance of habitat models developed using logistic regression. Ecological Modelling 133: 225-245.

R Development Core Team (2004). R: a language and environment for statistical computing. R Foundation for Statistical Computing: Vienna, Austria. URL: http:// www.R-project.org.
Singleton, G.R. (2008). House Mouse Mus musculus Linnaeus 1758 (pp 702-703). In: Van Dyke, S. and Strahan, R. (eds), The mammals of Australia, $3^{\text {rd }}$ edn. Reed New Holland: Sydney, Australia.

Spencer, W.B. (1896). Report on the work of the Horn Expedition to Central Australia. Part 2. Zoology. Dulau and Co.: London, U.K.

Start, A.N., Anstee, S.D. and Endersby, M. (2000). A review of the biology and conservation status of the Ngadji Pseudomys chapmani Kitchener 1980 (Rodentia: Muridae). CALMScience 3: 125-147.

Thorne, A.M. and Tyler, I.M. (1997). Mount Bruce, Western Australia, Sheet SF 50-11 International Index. 1:250 000 Geological Series Explanatory Notes. Australian Government Publishing Service: Canberra, Australia.

Van Dyck, S. and Strahan, R. (2008). The mammals of Australia, $3^{\text {rd }}$ edn. Reed New Holland: Sydney, Australia.

Van Vreeswyk, A.M.E. (2004). Resource condition (pp 385-400). In Van Vreeswyk, A.M.E., Payne, A.L., Leighton, L.A. and Hennig, P. (eds), An inventory and condition survey of the Pilbara Region, Western Australia. Technical Bulletin No. 92. Department of Agriculture: Perth, Australia.

Woinarski, J.C.Z., Braithwaite, R.W., Menkhorst, K.A., Griffin, S., Fisher, A. and Preece, N. (1992). Gradient analysis of the distribution of mammals in Stage III of Kakadu National Park, with a review of the distribution patterns of mammals across northwestern Australia. Wildlife Research 19: 233-262.

Woolley, P.A. (2008). Woolley's Pseudantechinus Pseudantechinus woolleyae Kitchener and Caputi 1988 (pp 76-77). In: Van Dyke, S. and Strahan, R. (eds), The mammals of Australia, $3^{\text {rd }}$ edn. Reed New Holland: Sydney, Australia. 


\section{APPENDIX 1}

Plots of fitted values in relation to each predictor for each species: A) DROS - Dasykaluta rosamondae; B) LLAK - Leggadina lakedownsensis; C) MMUS - Mus musculus; D) NTIM - Ningaui timealeyi; E) PCHA Pseudomys chapmani; F) PDEL - Pseudomys delicatulus; G) PDES - Pseudomys desertor; H) PHER - Pseudomys hermannsburgensis; I) PLA1 - Planigale sp. 1; J) PLA2 - Planigale sp. 2; K) PWOO - Pseudantechinus woolleyae; L) SMAC - Sminthopsis macroura; M) SYOU - Sminthopsis youngsoni; and N) ZARG - Zyzomys argurus. Values for positive observations only are shown. wtm = weighted mean of fitted values.

A.

DROS,$w t m=311.38$

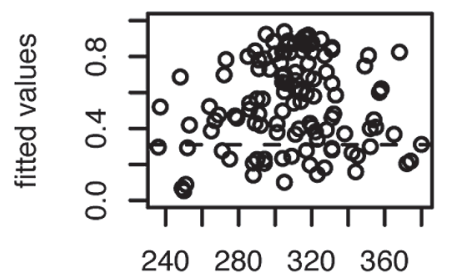

RAIN
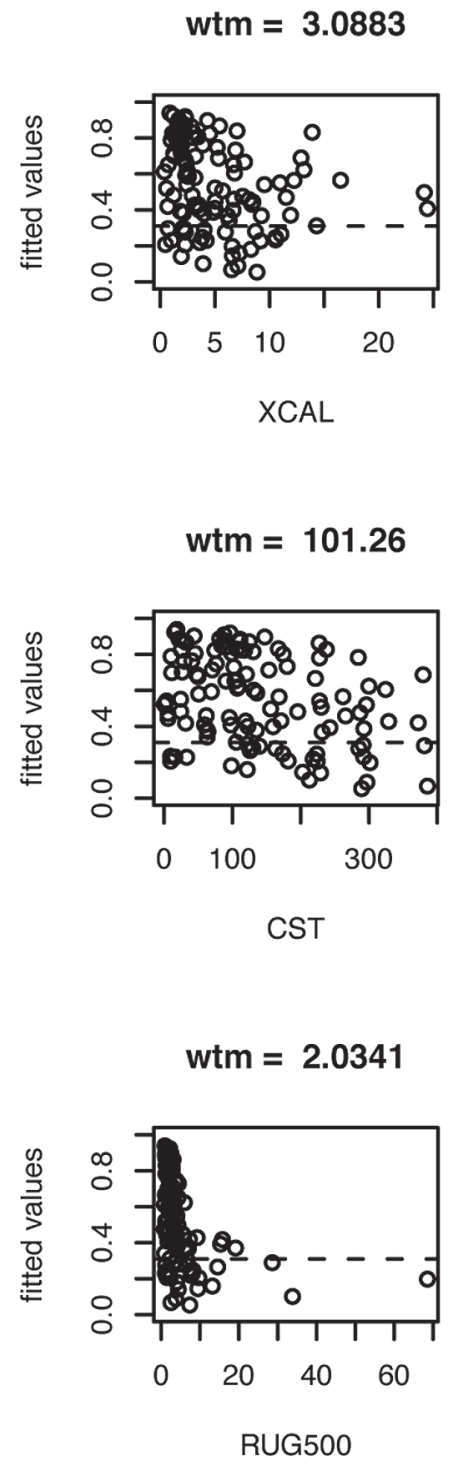

$w t m=7.093$

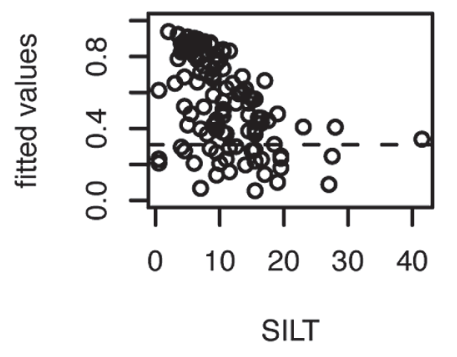

$w t m=13.06$

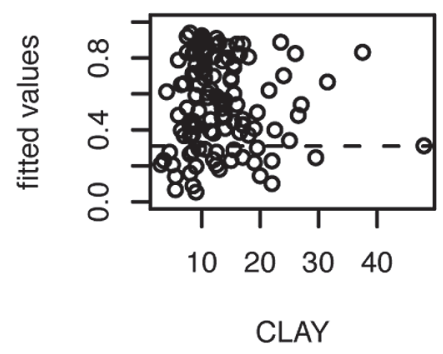

wtm $=2.2869$

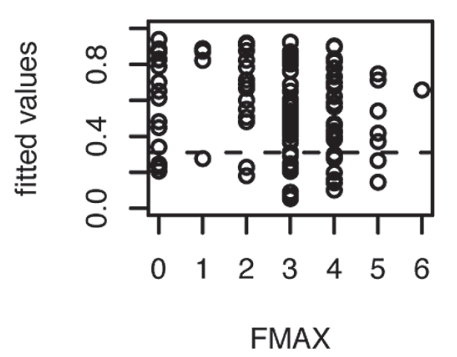

$\mathrm{wtm}=4.997$

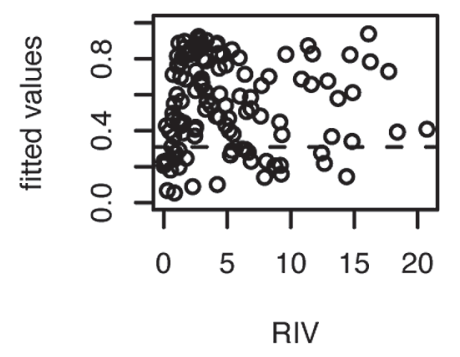

$w t m=0.027272$

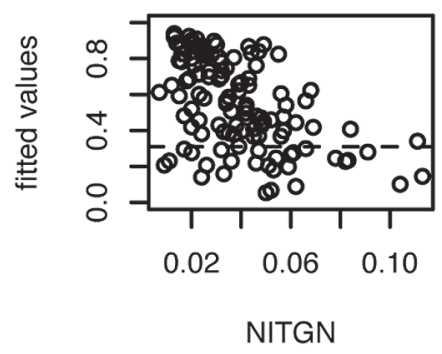

$w t m=8.7$

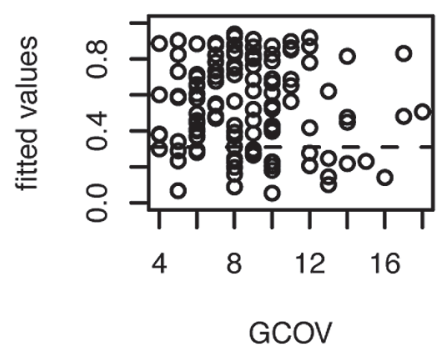

$w \operatorname{tm}=0.3481$

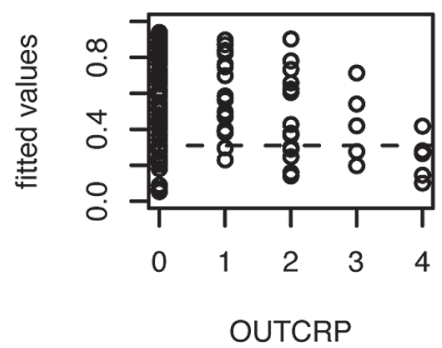



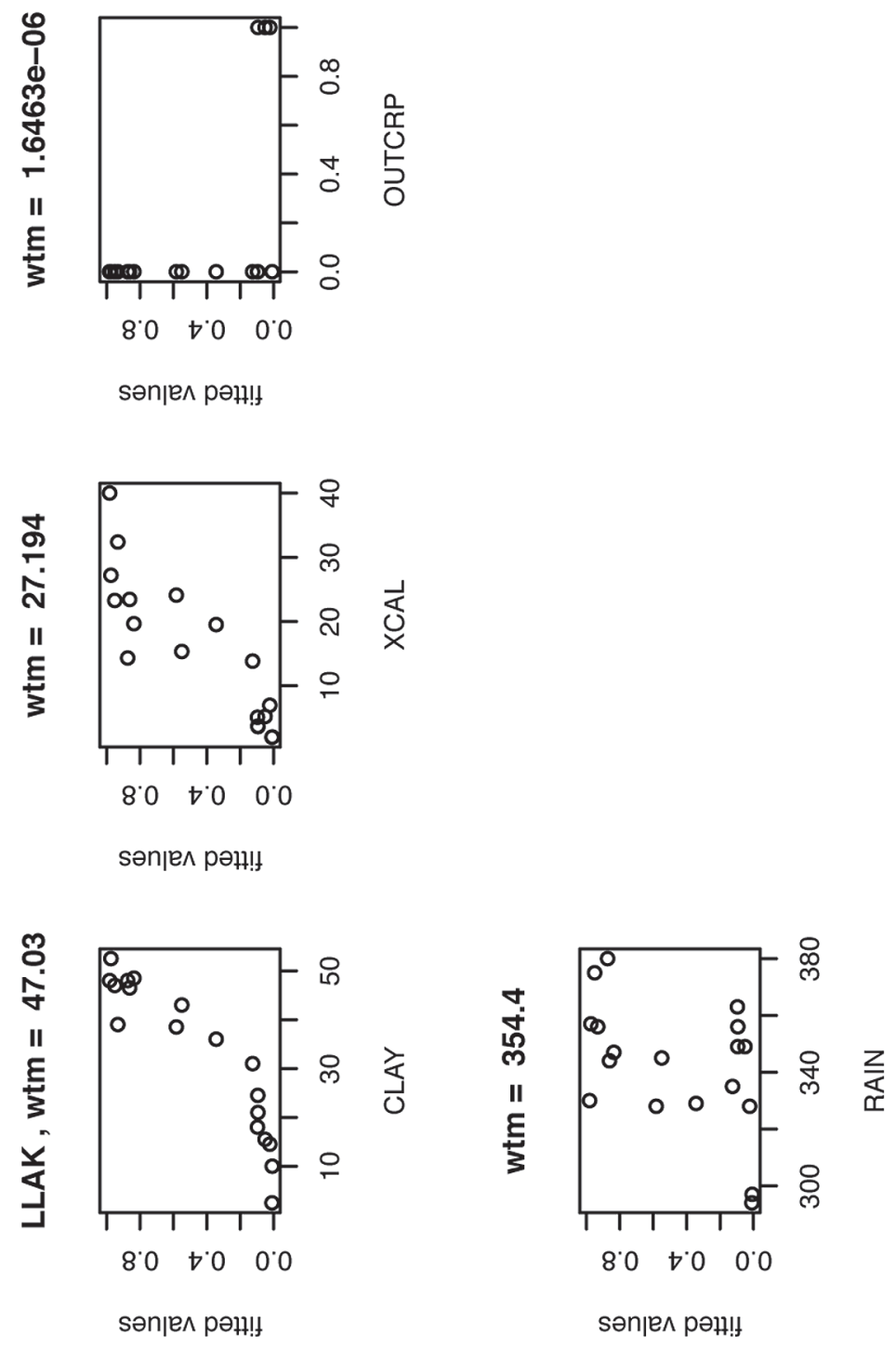

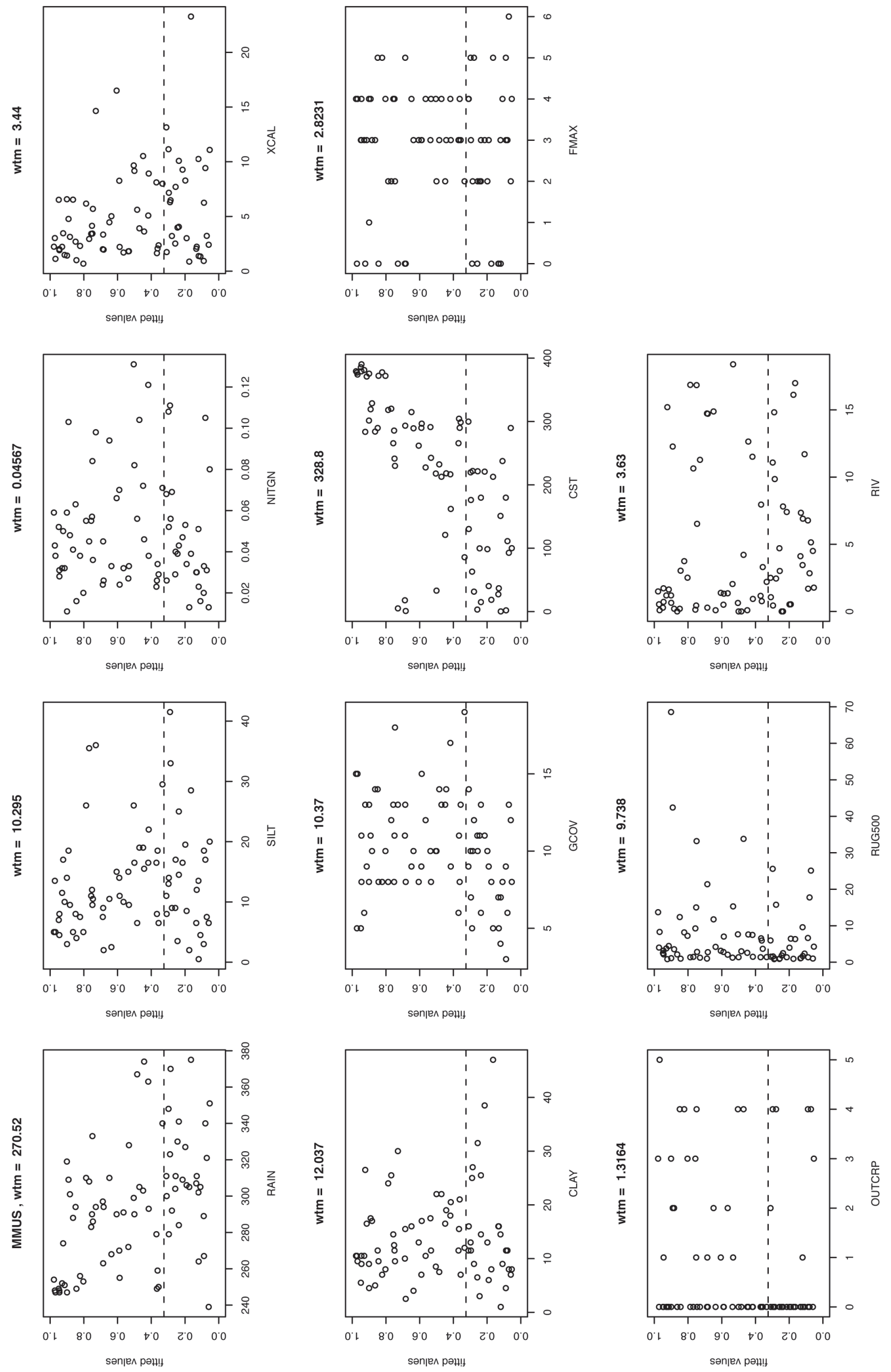
D.
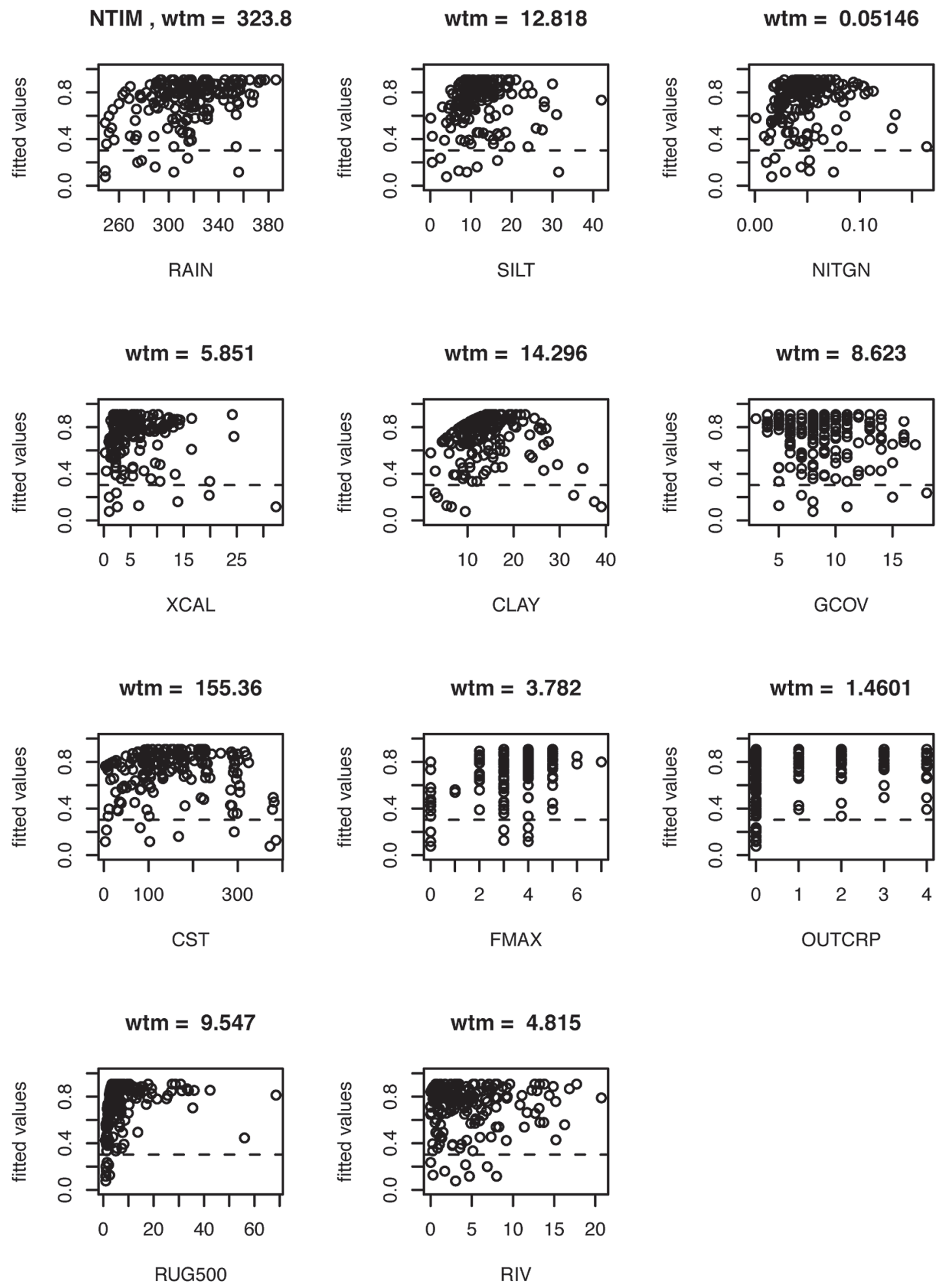
E.
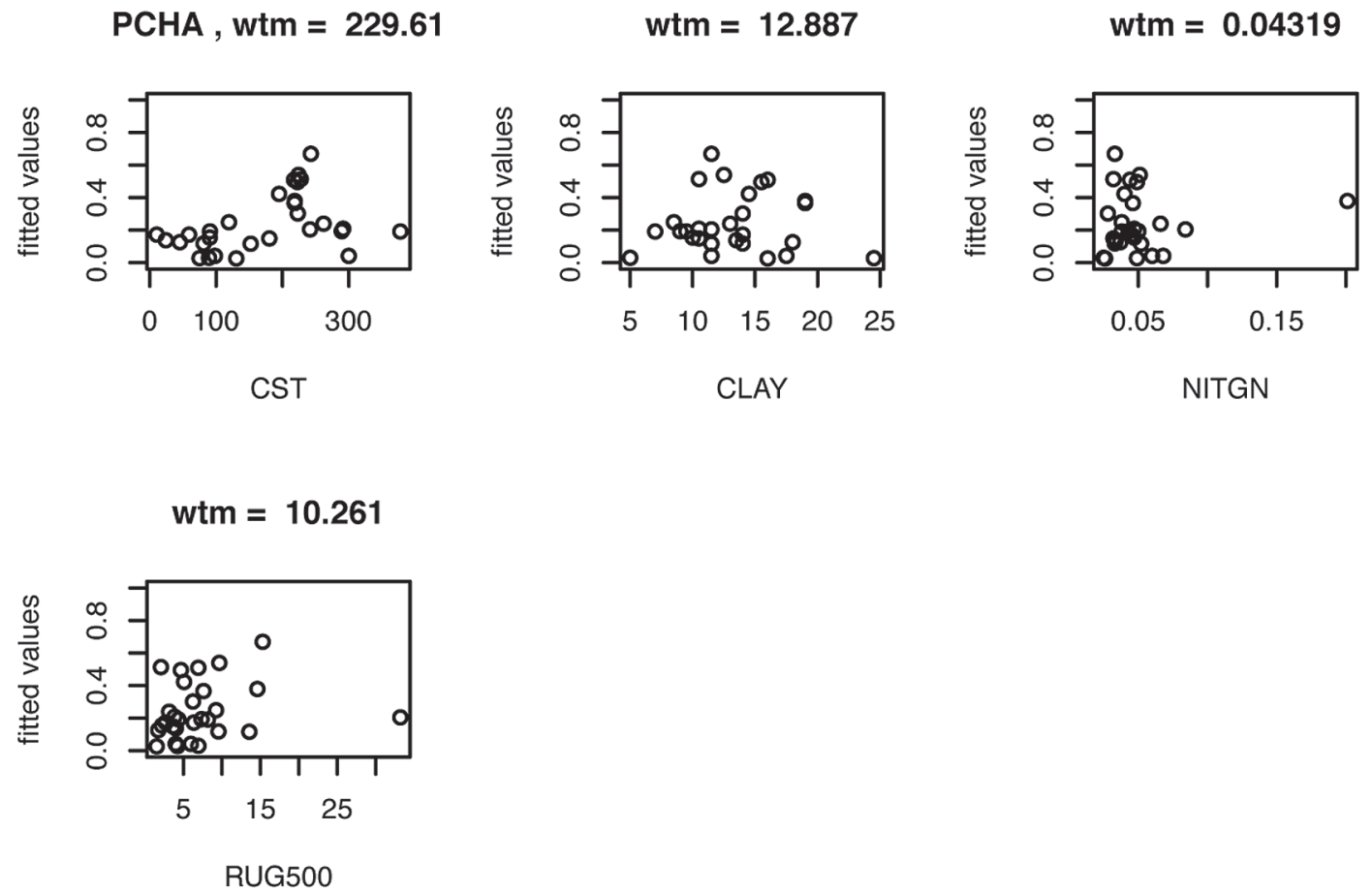

F.

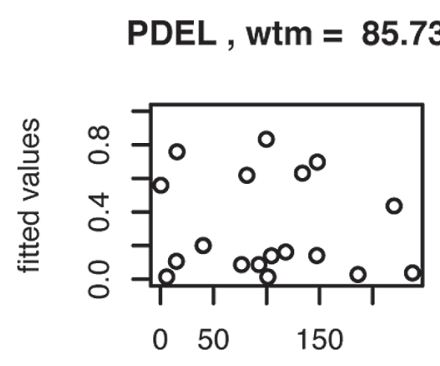

CST

$w t m=3.316$

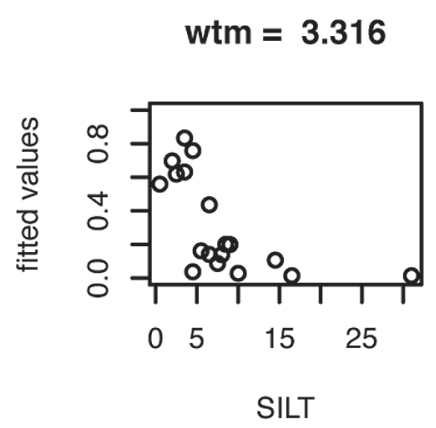

SILT

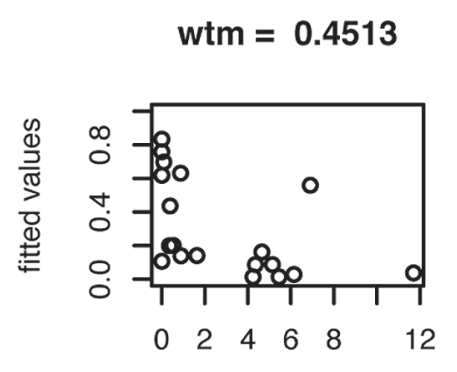

RIV

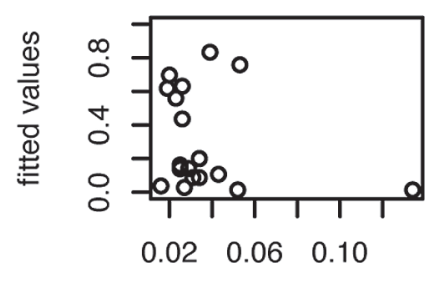

NITGN 
G.
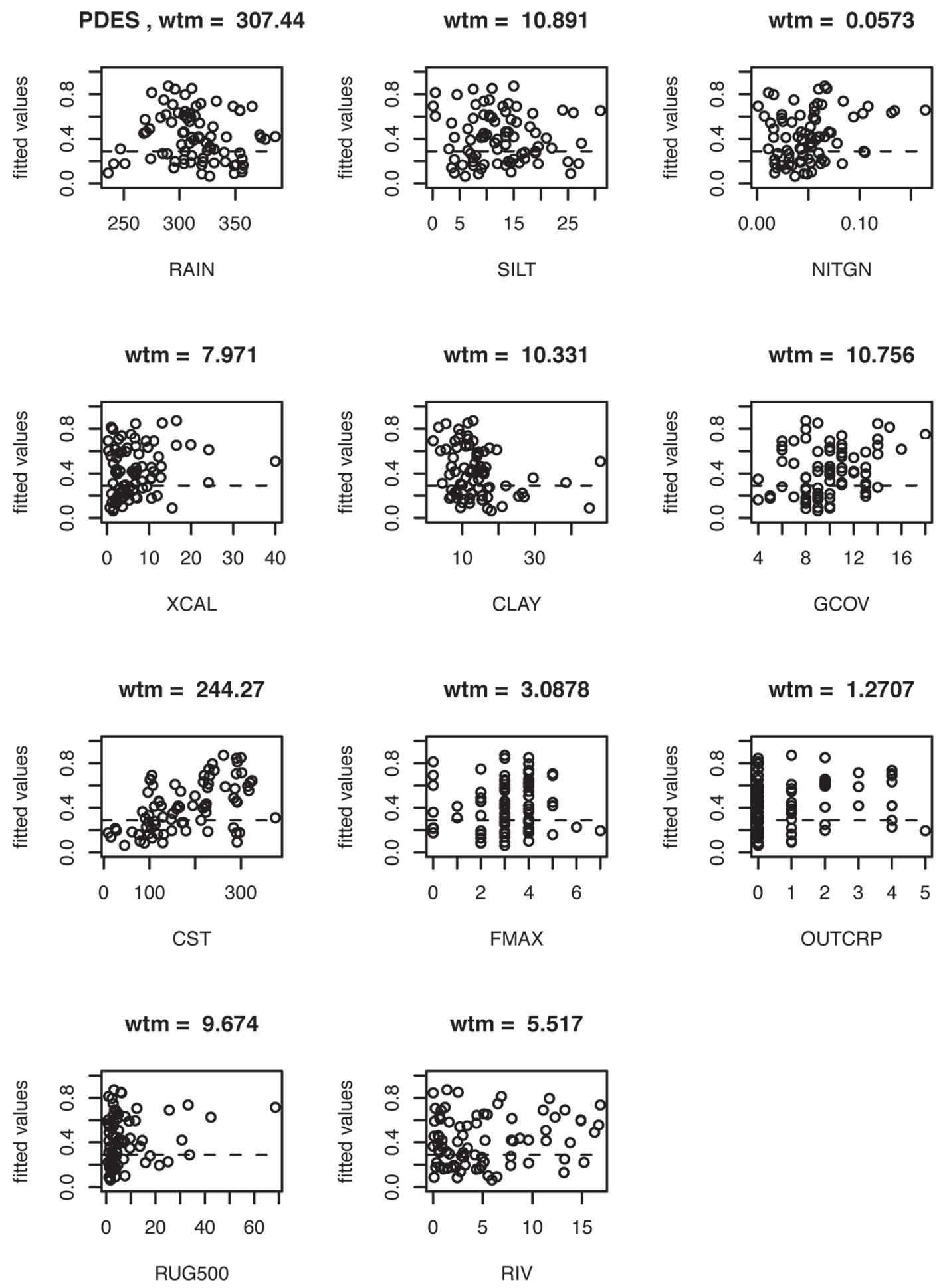
H.

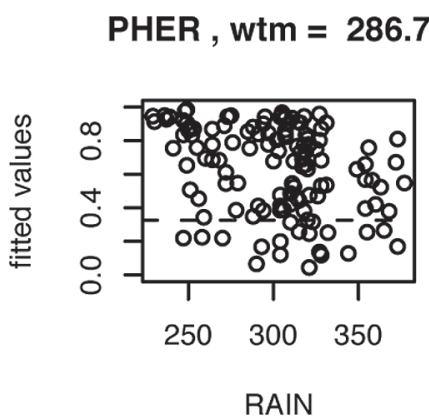

wtm $=1.9047$

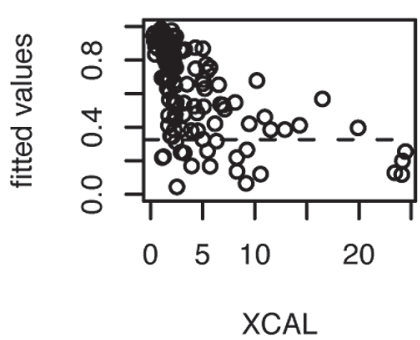

$w t m=177.52$

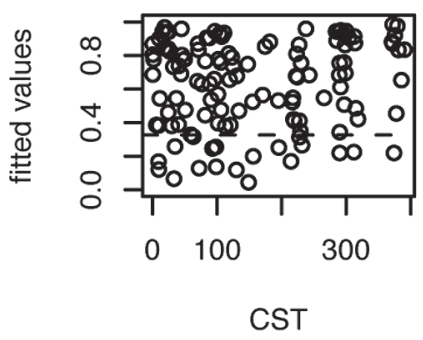

$w t m=2.7172$

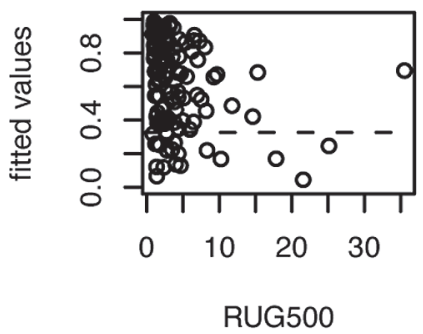

$w \operatorname{tm}=5.544$

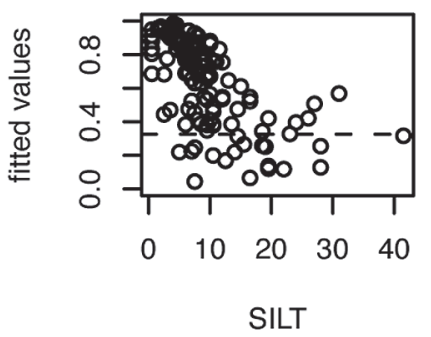

wtm $=9.599$

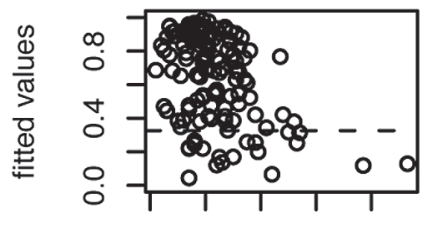

CLAY

$w t m=1.871$

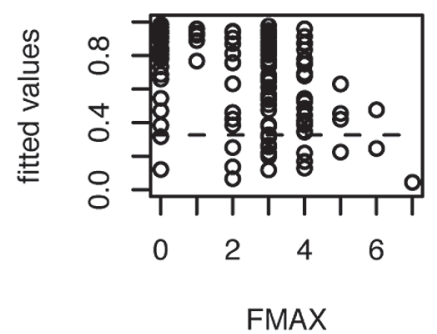

$\mathrm{wtm}=6.362$

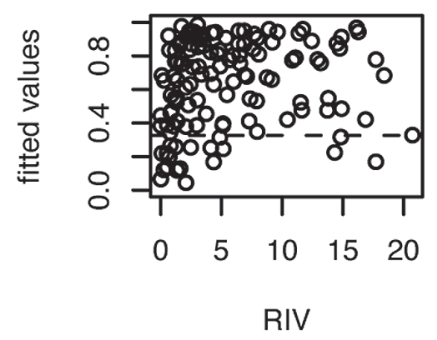

wtm $=0.022049$

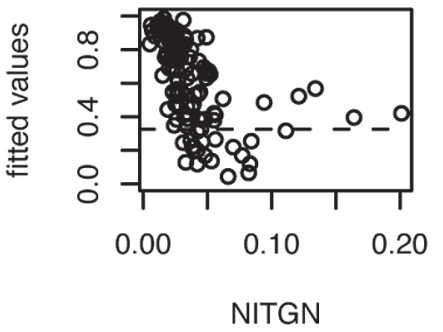

wtm $=9.353$

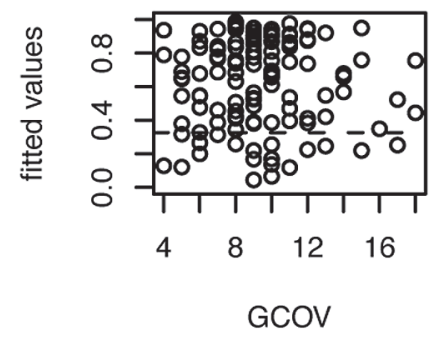

$w \operatorname{tm}=0.14719$

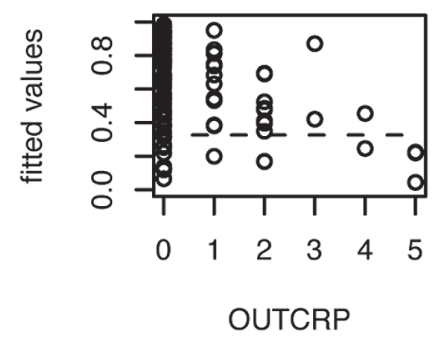


I.
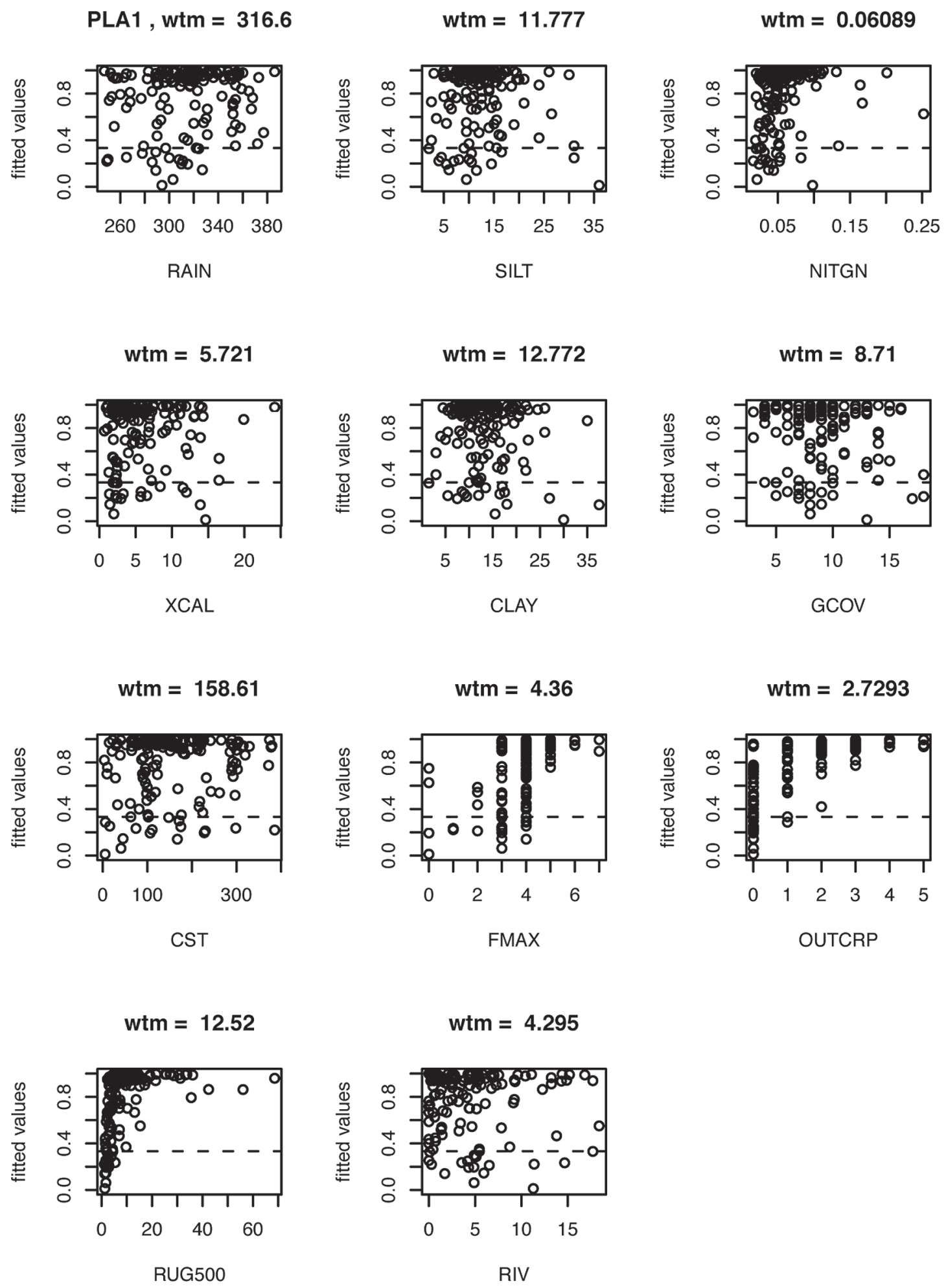
J.
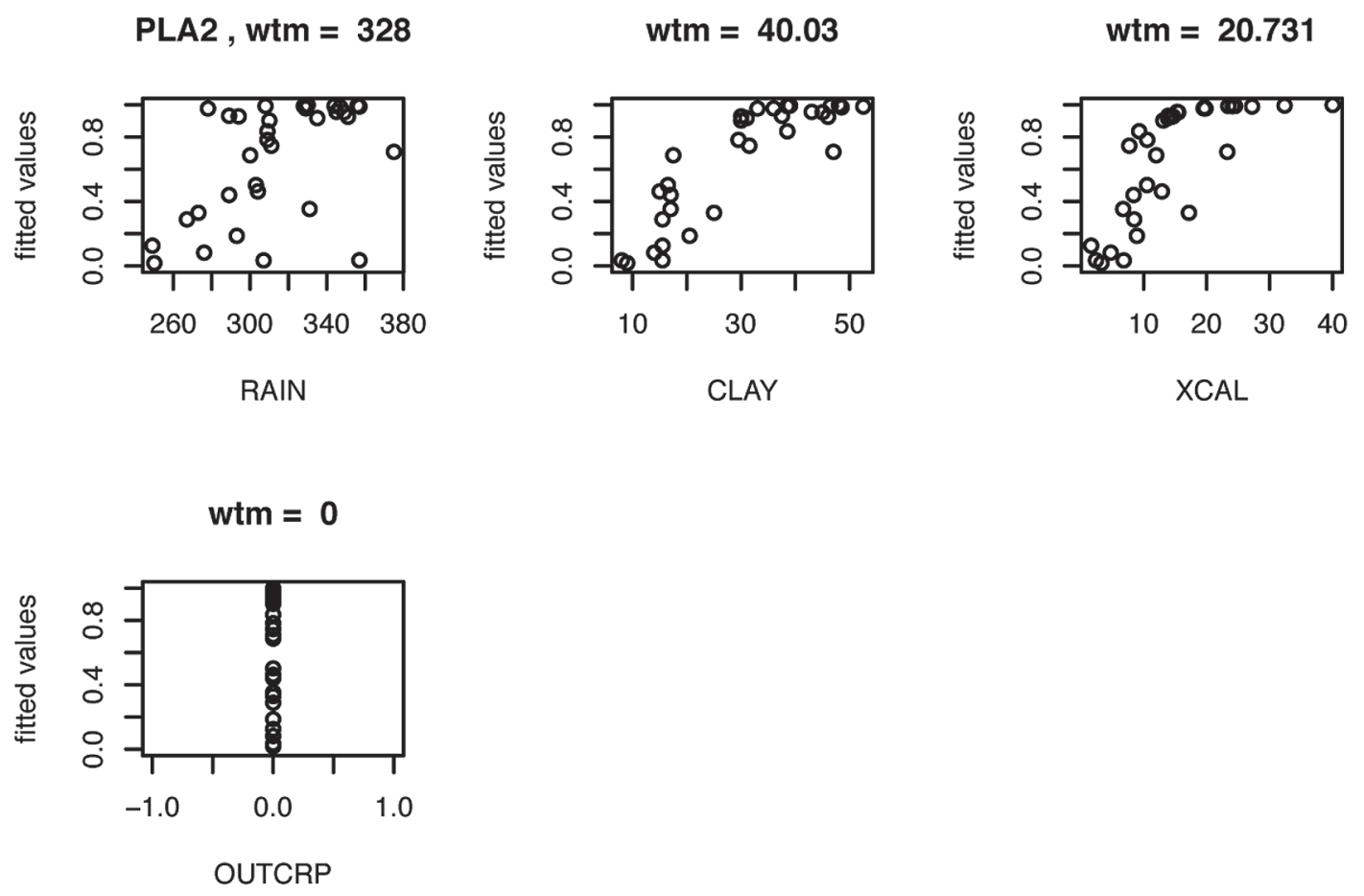

K.
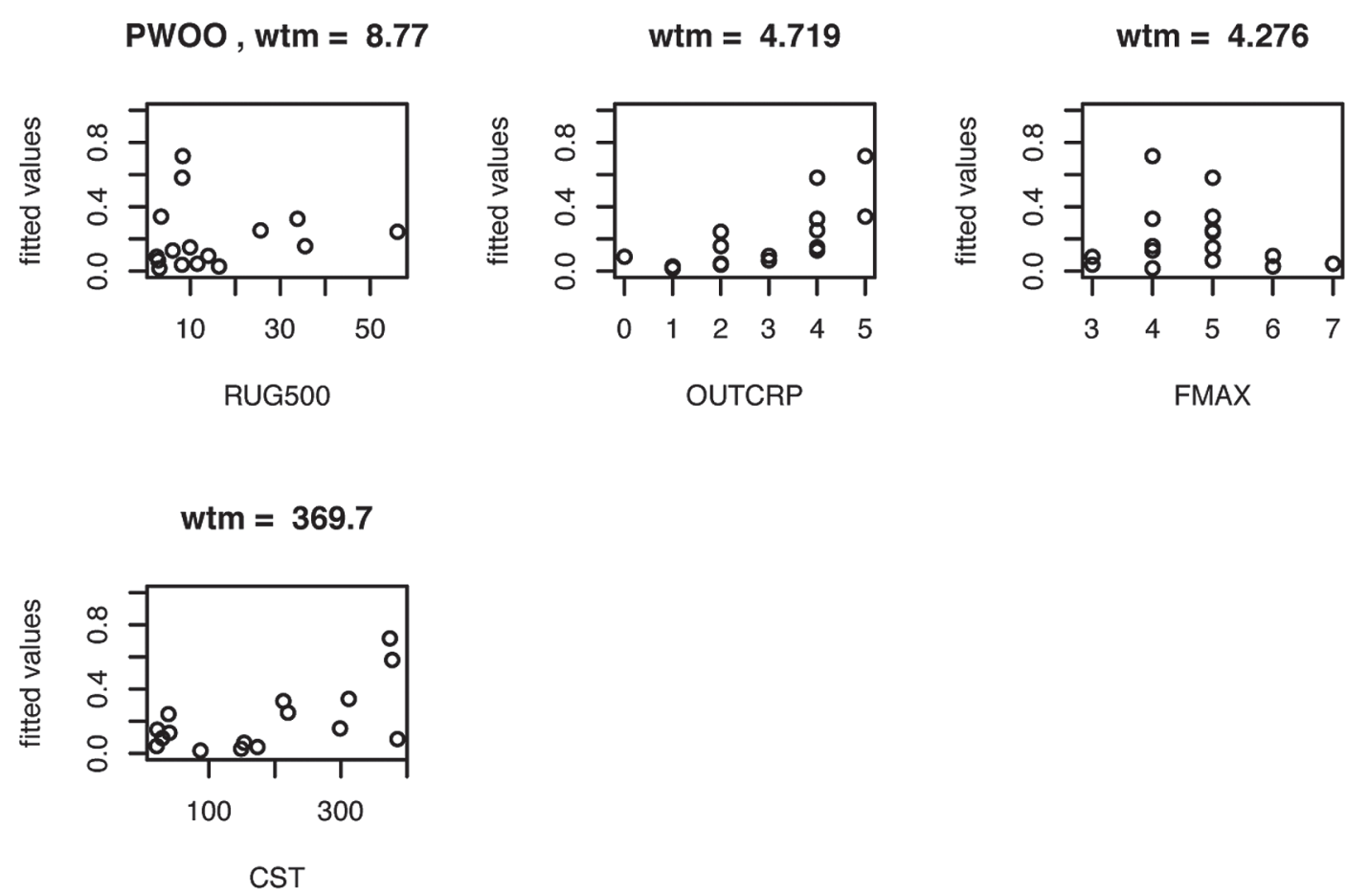
L.
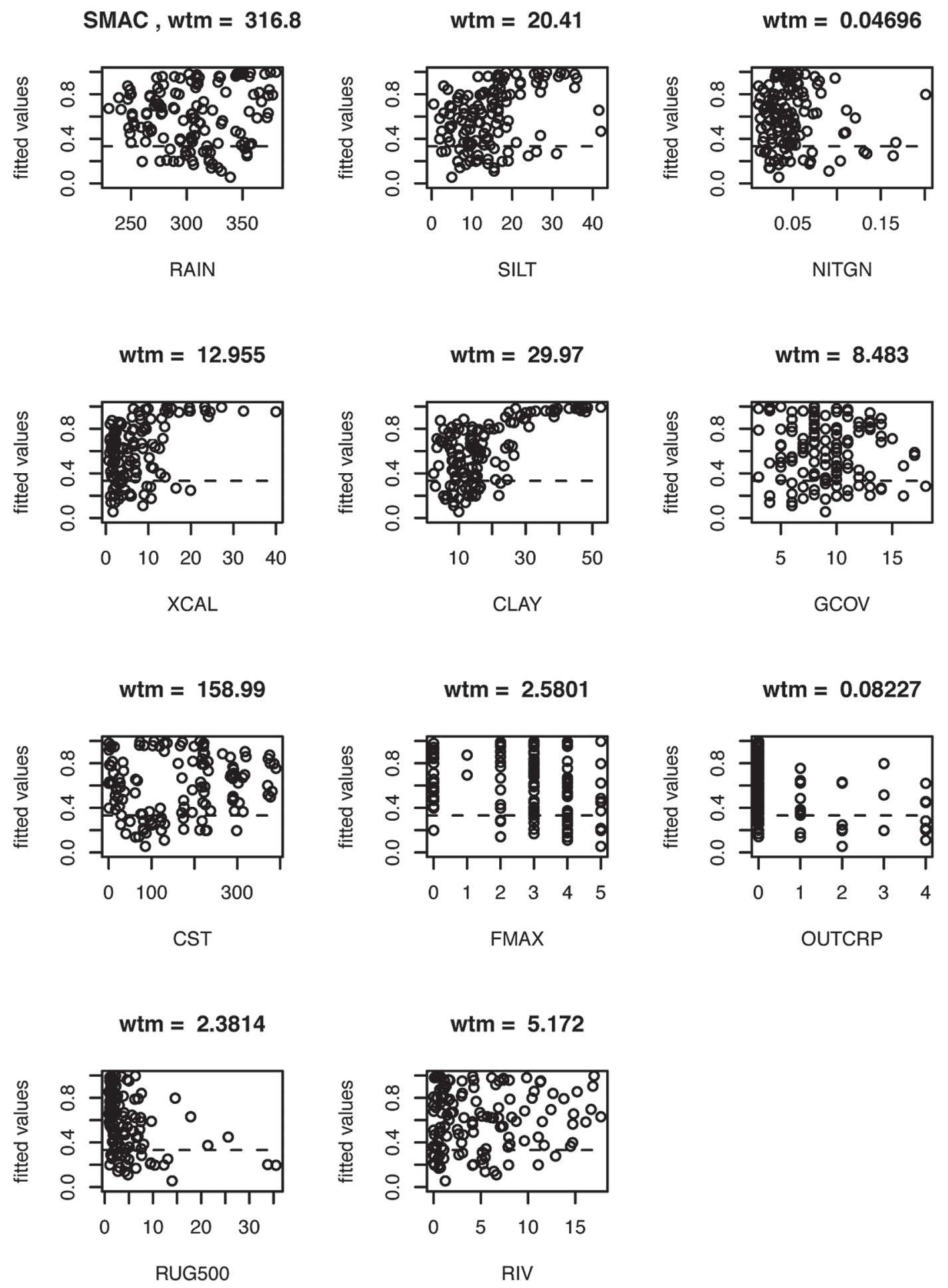
M.
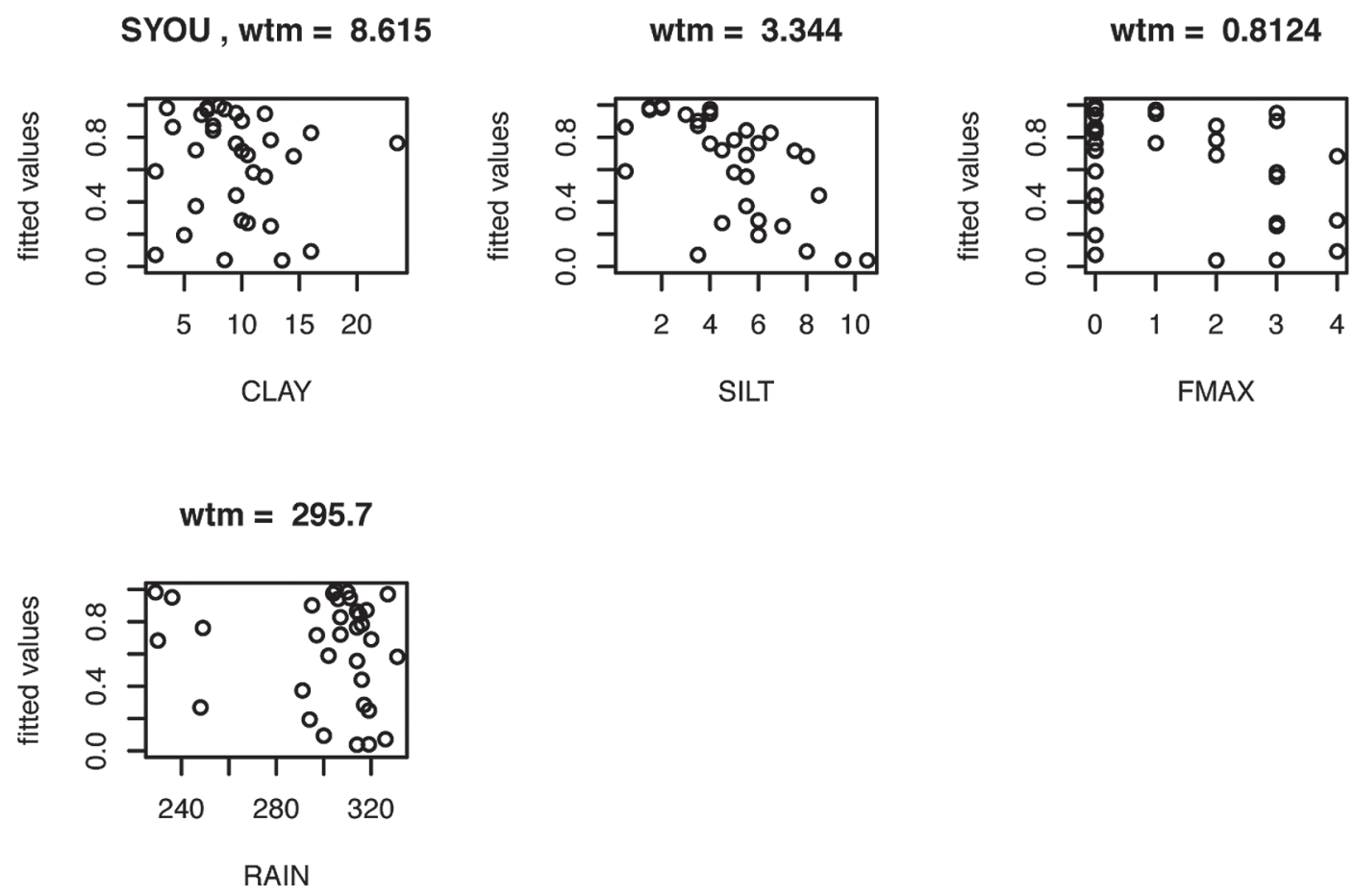

N.

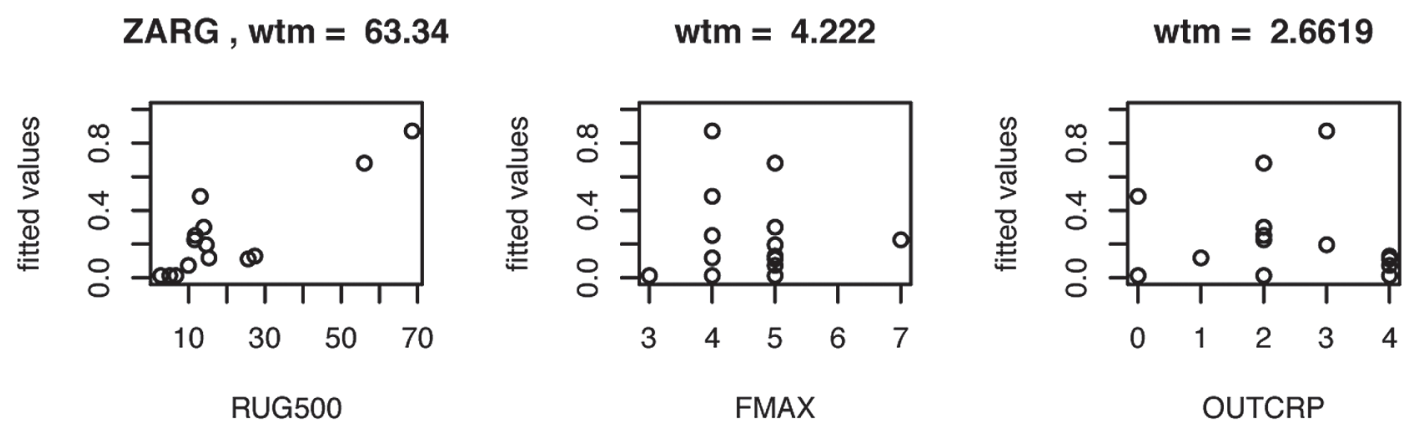




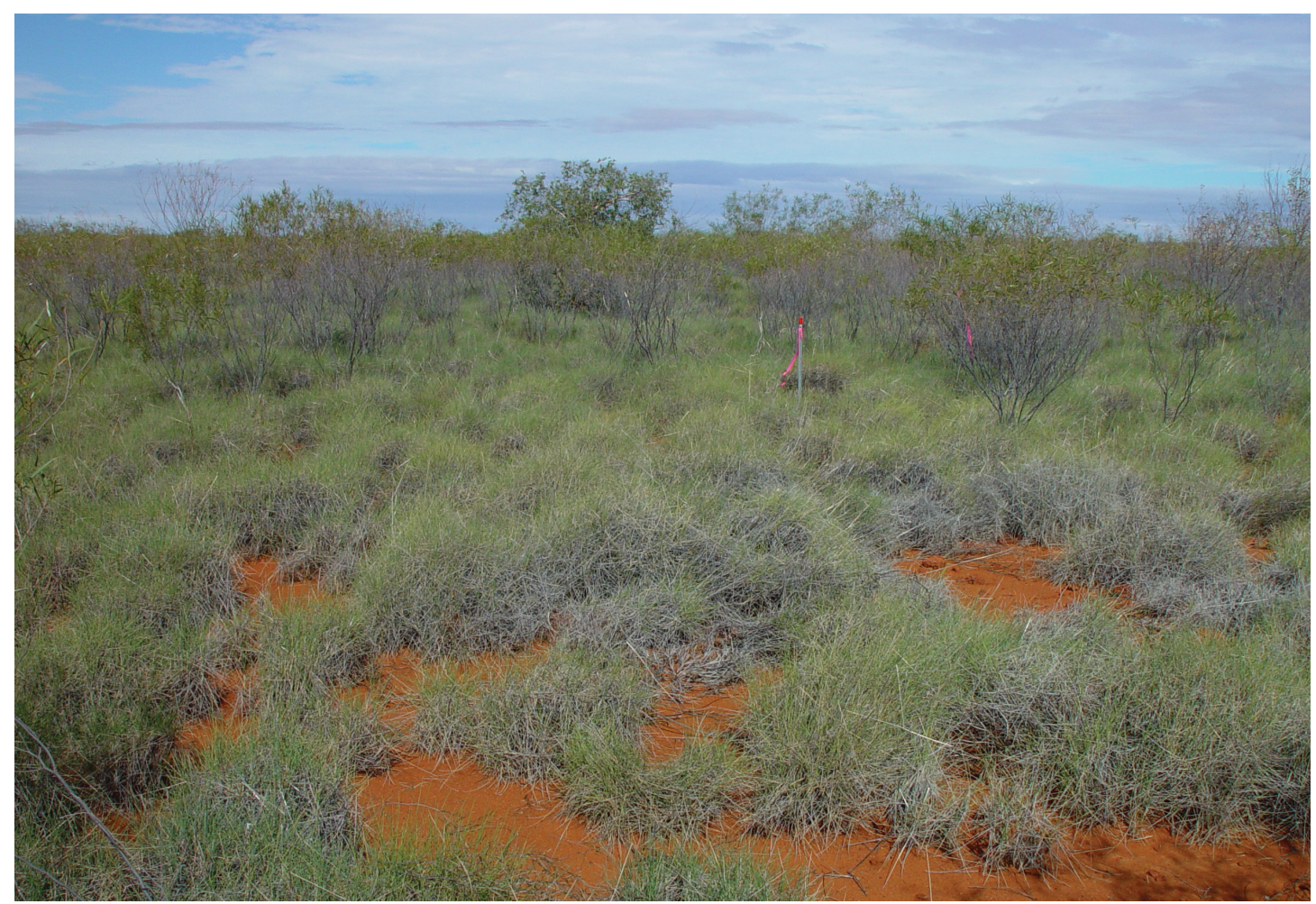

Plate 1 Sandplains in the Pilbara are usually firm because the red sand is slightly clayey. Site MBW8 (2104'16"S, 118 40'55"E), a typical example, supported mallee (Corymbia hamersleyana) and shrubs (Acacia ancistrocarpa and A. inaequilatera) over hummock grass (Triodia sp.) (N.L.McKenzie).

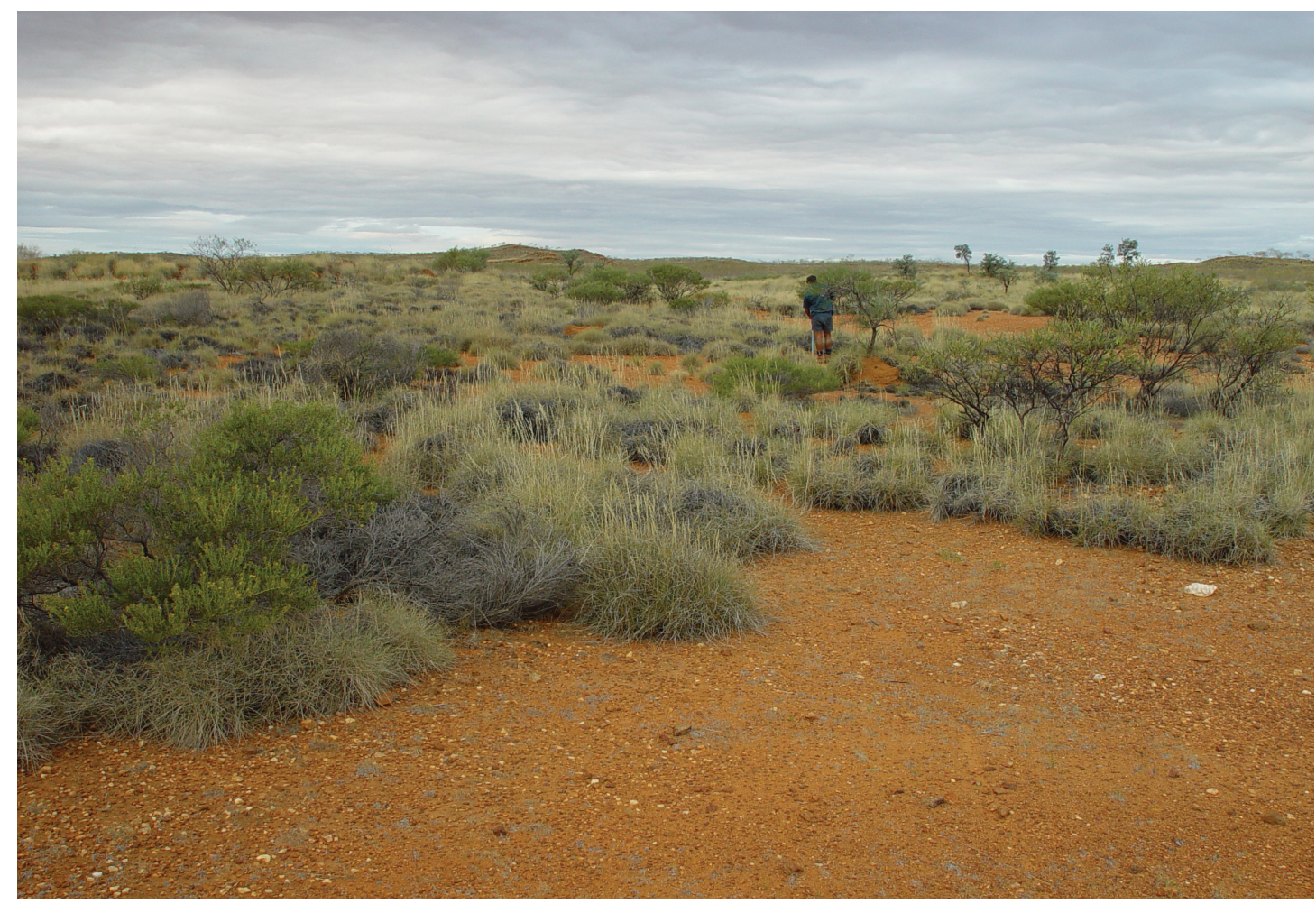

Plate 2 Large areas of the northern Pilbara are covered by plains of red sand and granitoid grit, containing gravel and quartzite pebbles that mantle massive sheet granite. For example, site MBW12 (21 $\left.24^{\prime} 03^{\prime \prime S}, 118^{\circ} 42^{\prime} 36^{\prime \prime E}\right)$ supported shrubs (Acacia bivenosa and A. stellaticeps) over hummock and bunch grass (Triodia pungens, T. wiseana, Yakirra sp. and Eriachne sp.) and sedges (N.L. McKenzie). 


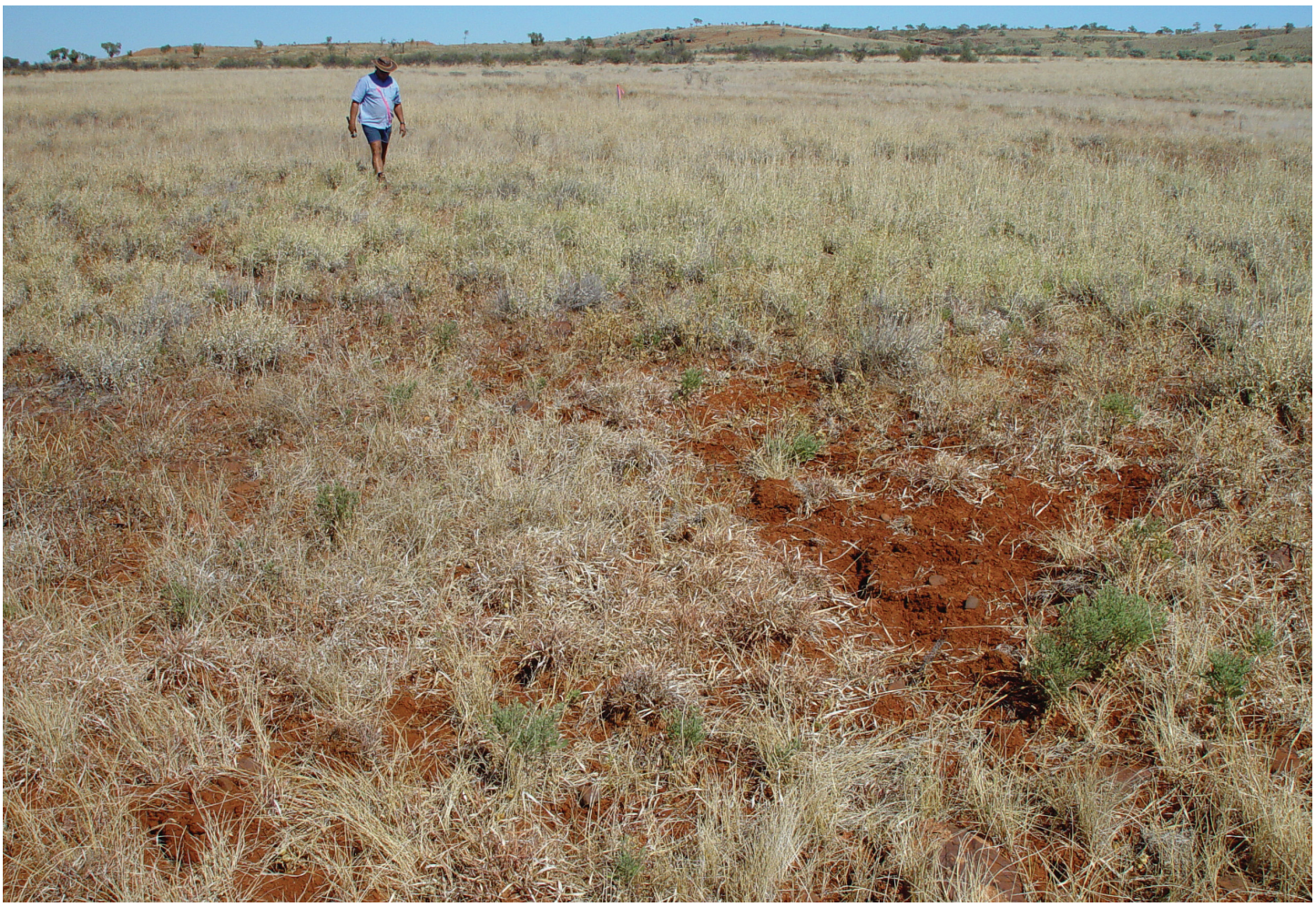

Plate 3 Flat and gently sloping plains of cracking and heaving clay occur in many parts of the Pilbara and are characterised by tussock grassland (Astrebla sp., Eragrostis spp. and Aristida sp.) and herbs (RHNW08: 2206'24"S, 11900'04"E) (N.L. McKenzie).

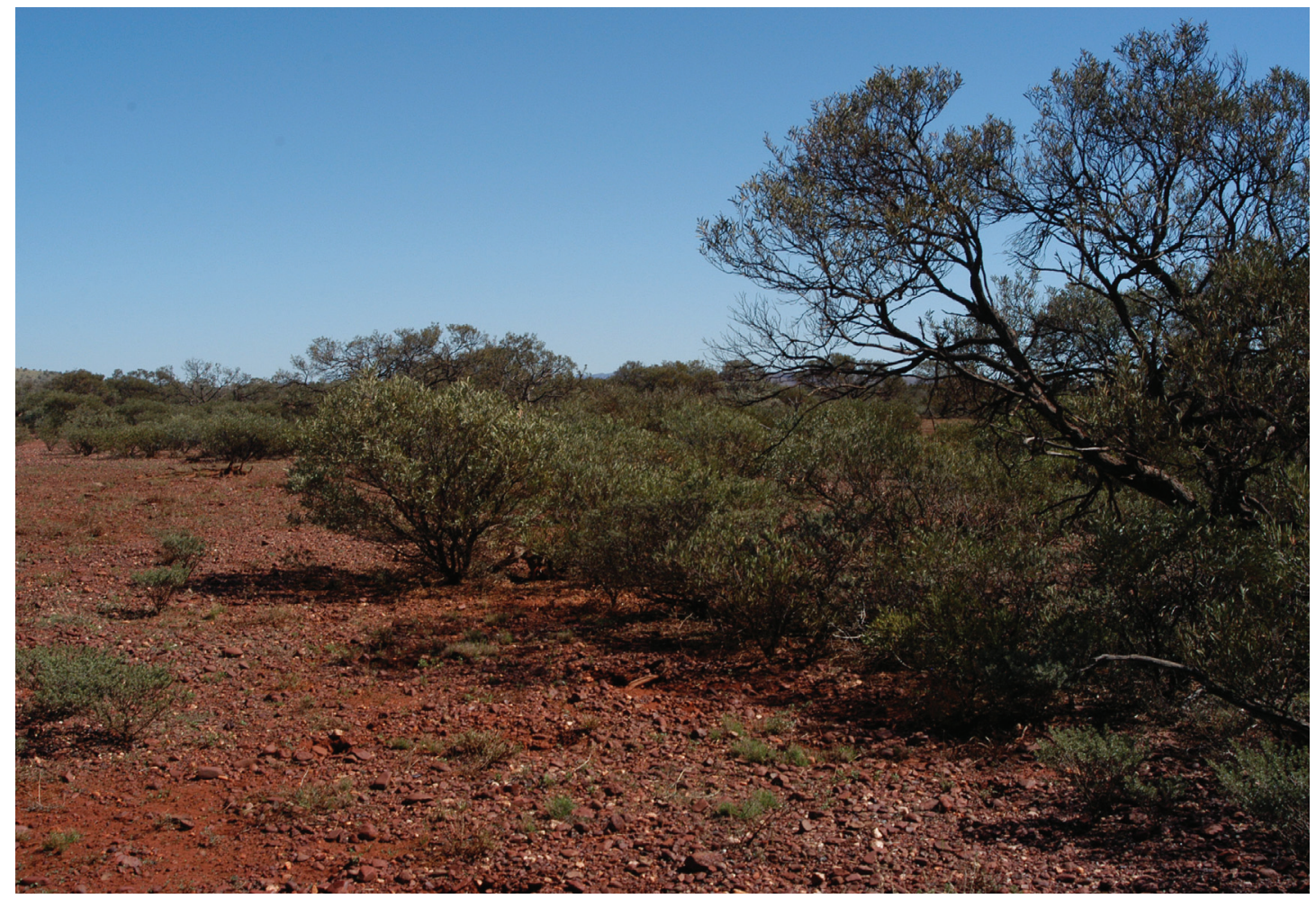

Plate 4 Flat alluvial plains and very gentle slopes of cracking and mulching gilgai clay often have a surface strew of rocks and gravel. Typical vegetation comprises the shrub (Acacia xiphophylla) over tussock, bunch and hummock grass (Aristida sp., Sporobolus sp., Dichanthium sp., Yakirra sp. and Triodia pungens) (TCMBW08: 22³0'13"S, 117²42'14"E) (A.H. Burbidge). 


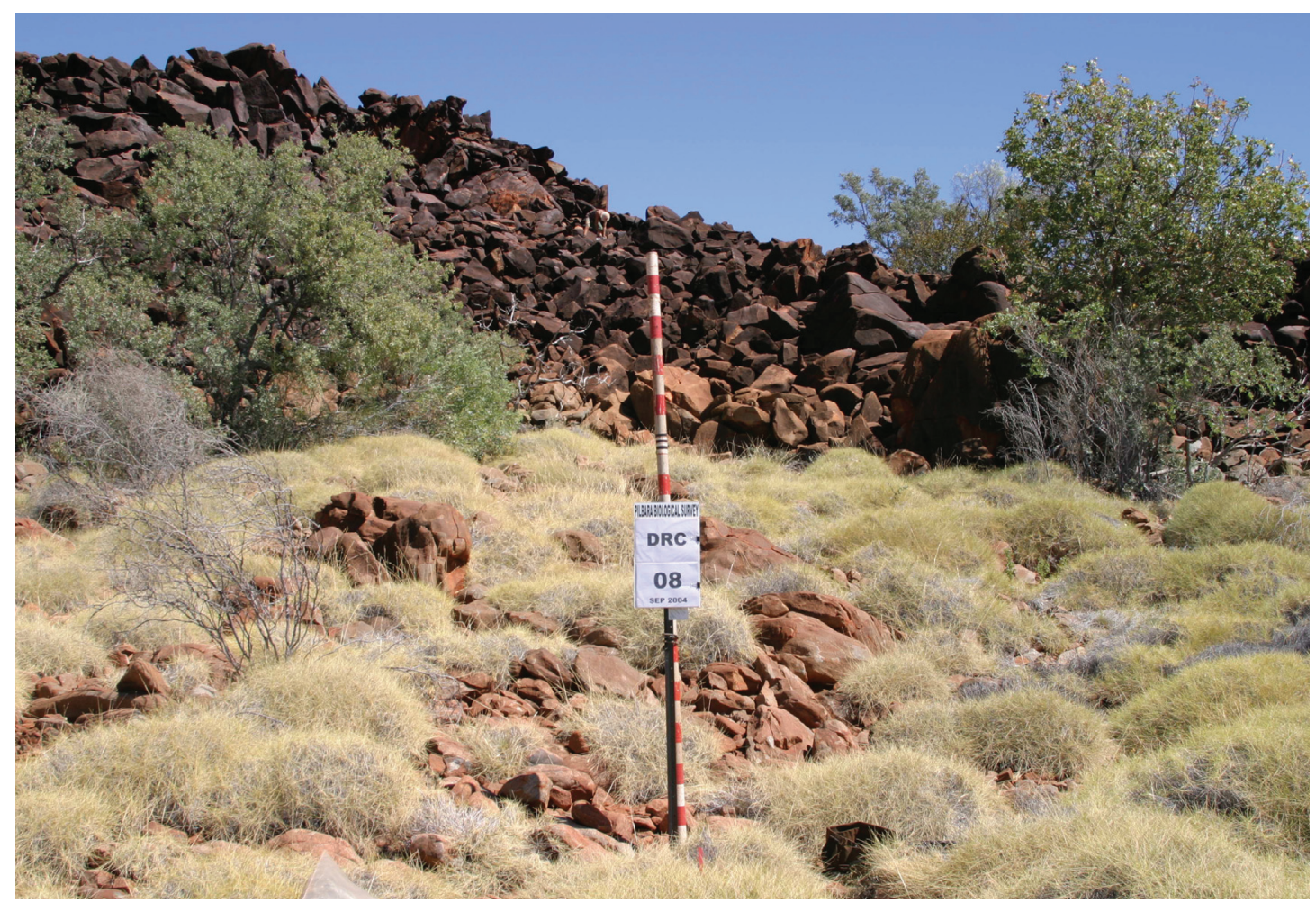

Plate 5 Steep boulder slopes of Archaean rock, with patches of soil on foot-slopes and in crevices and depressions, are common in the Pilbara. They support scattered Terminalia canescens and Brachychiton acuminatus trees, shrubs such as Acacia bivenosa and A. arida, hummock grass (Triodia sp.), tussock grass (Cenchrus ciliaris) and herbs (DRC08: 2051'09"S, 11705'46"E) (S. van Leeuwen).

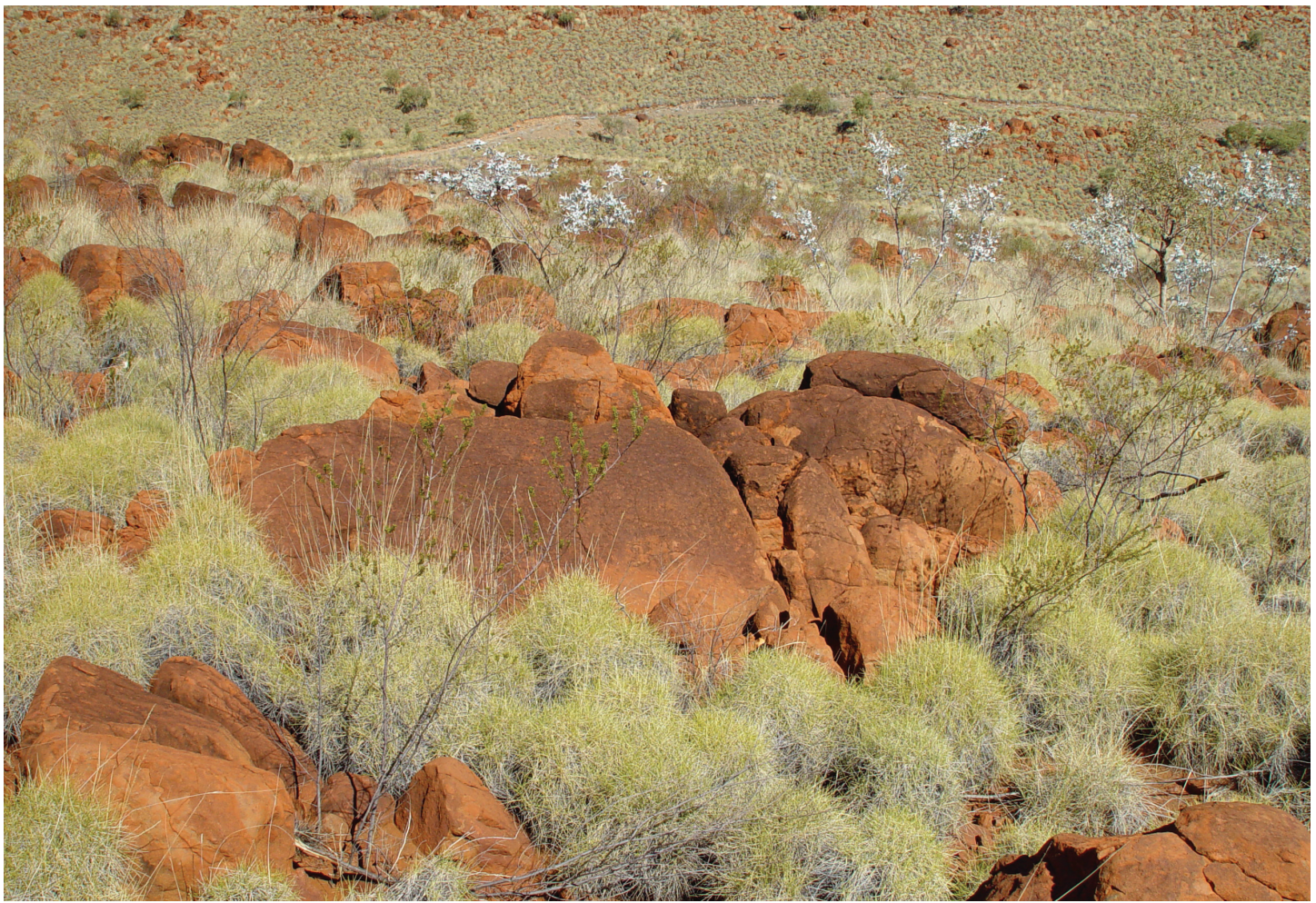

Plate 6 Example of a massive basalt scree slope in the Pilbara. Areas of decomposing basalt occur in a shallow clay matrix, and support scattered trees (Corymbia hamersleyana), mallee (Eucalyptus gamophylla) and shrubs (Acacia maitlandii) over hummock and bunch grasses (Triodia pungens, T. wiseana and Cymbopogon sp.) (TCMBE13: 22 $\left.41^{\prime} 57^{\prime \prime S}, 117^{\circ} 48^{\prime} 58^{\prime \prime E}\right)$ (N.L. McKenzie). 


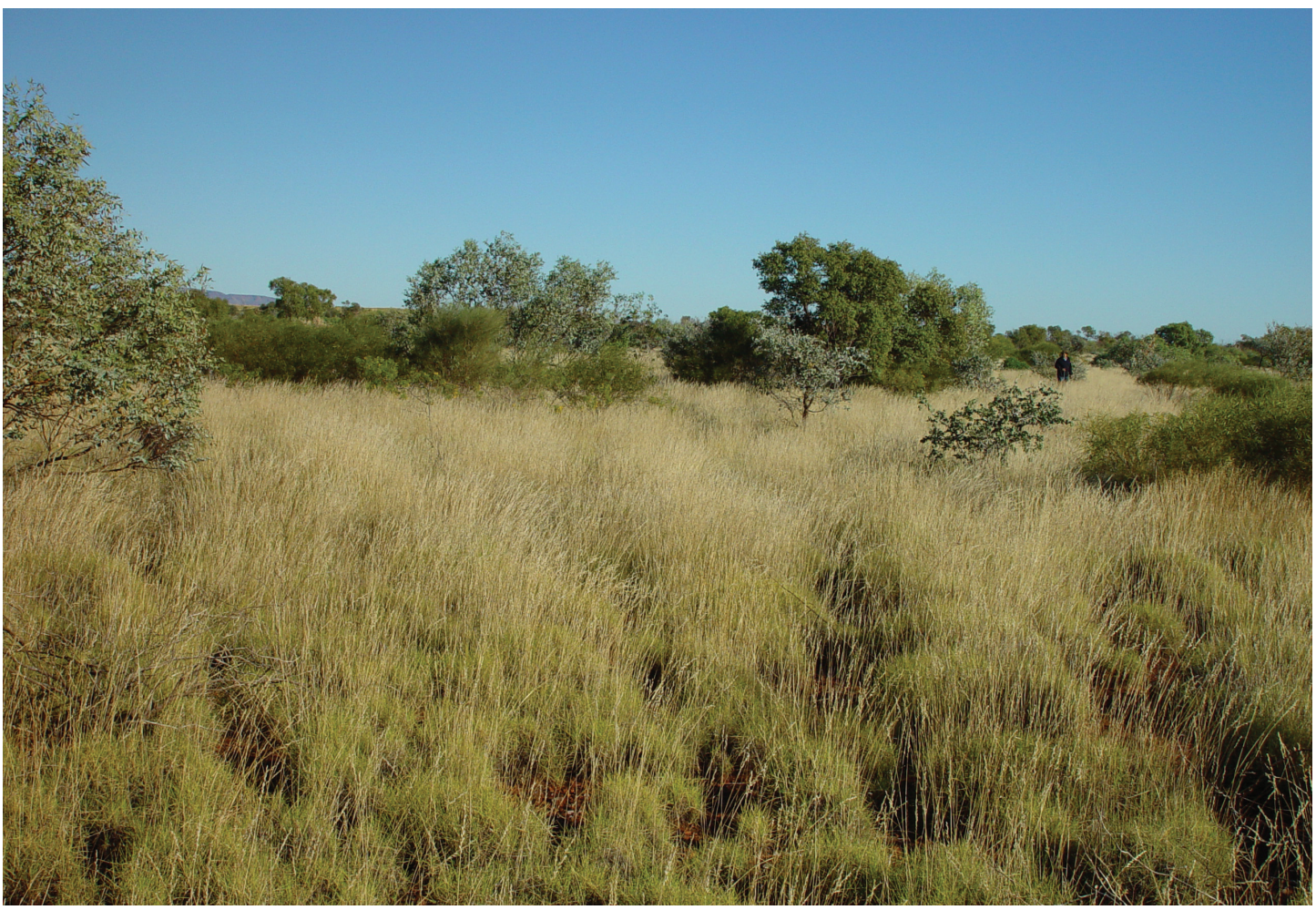

Plate $7 \quad$ Flat and undulating alluvial plains of sandy clay with rock fragments in the soil profile are common in the Pilbara. Site RHNW03 (22 $\left.27^{\prime} 59^{\prime \prime} S 119^{\circ} 01^{\prime} 22^{\prime \prime E}\right)$, a typical example, supported scattered Corymbia hamersleyana, C. deserticola and Eucalyptus gamophylla trees and mallees over Acacia spp. and Corchorus sp. shrubs, and Triodia basedowii hummock grass (N.L. McKenzie).

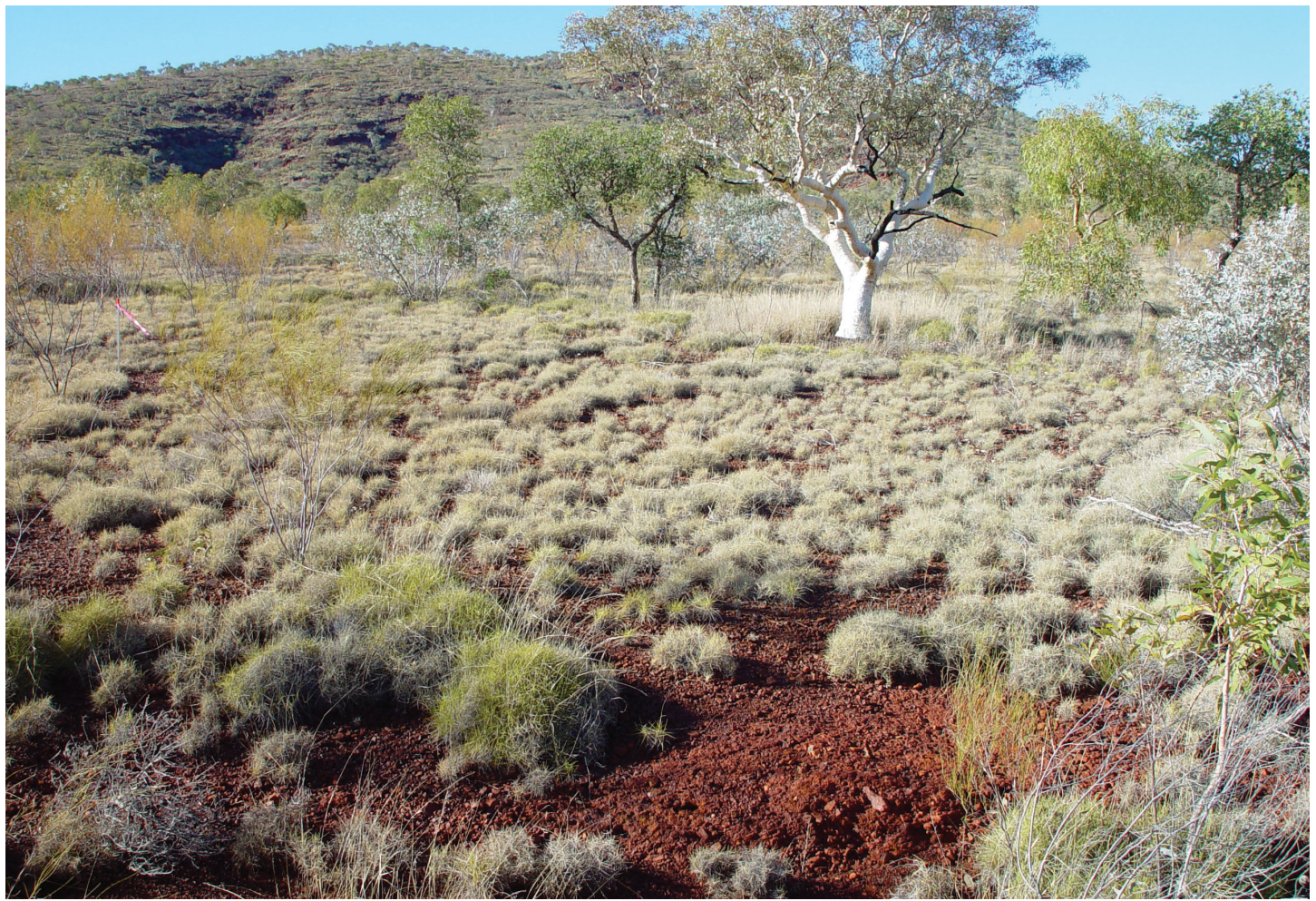

Plate 8 Undulating plains and valley floors of Cenozoic and Quaternary colluvium, comprising rock fragments and fine gravel in a red sandy clay matrix, are widespread in the southern Pilbara. For example, site TCMBE01 (22 $\left.34^{\prime} 17^{\prime \prime} S, 118^{\circ} 18^{\prime} 25^{\prime \prime E}\right)$ supported scattered trees and mallee (Eucalyptus leucophloia, E. gamophylla, Corymbia deserticola and C. hamersleyana) over shrubs (Acacia spp. and Indigofera monophylla), hummock grass (Triodia wiseana, T. basedowii), tussock grass (Themeda triandra), bunch grass (Paraneurachne muelleri) and sedges (N.L. McKenzie). 